\title{
Einführung und erste historische Problematisierung
}

\section{Problemherleitung und Fragestellung}

In der vorliegenden Monographie wird es darum gehen, sich aus literaturwissenschaftlich-semiotischer Perspektive mit der im ,abendländischen‘ Kulturraum präsenten Vorstellung auseinanderzusetzen, Schriftzeichen könnten Gedanken, Dinge oder Personen und deren Taten verewigen, also für alle Zeiten festhalten. Diese Vorstellung aber ist nicht eine, die nur etwa Grabinschriften oder dichterische Werke einschließt. Sie erstreckt sich ebenfalls auf wissenschaftliche Arbeiten. Eine Monographie, die sich wissenschaftlich mit dieser Vorstellung auseinandersetzt, hat folglich immer auch und von Anfang an kritisch zu hinterfragen, ob sie nicht bereits selbst darum bemüht ist, Verewigung anzustreben oder eigenes Überdauern $\mathrm{zu}$ behaupten. In diesem Sinne soll eine erste derartige Hinterfragung in den Gegenstand des vorliegenden Buches einführen - und zwar anhand der Widmung, wie sie in Dissertationsschriften üblich und auch diesem Kapitel vorangestellt ist.

Es ließe sich ganz grundsätzlich fragen, weshalb sich Widmungen - sei es im Falle belletristischer oder wissenschaftlicher Werke - bis in die ,bürgerliche', nicht aristokratisch-höfische Gesellschaft des 21. Jahrhunderts erhalten haben. ${ }^{1}$ Der adlige Geldgeber, dessen Erwähnung in einer Widmung einst notwendig war, wurde schon seit geraumer Zeit ersetzt, im Falle einer Dissertationsschrift im deutschen Sprachraum überwiegend durch staatliche Institutionen. Die Widmungen richten sich heute denn auch nicht mehr an die adlige Herrschaft, sondern haben sich auf die Familie - bei den Dissertationsschriften gemeinhin auf die Eltern - der jeweiligen Autorinnen und Autoren übertragen. In dieser Übertragung spiegelt sich der Aufstieg des (Bildungs-)Bürgertums, eines Bürgertums, das die moderne Universität seit dem ausgehenden 18. Jahrhundert trägt und zu dessen Konstitution die

1 Zum Form- und Funktionswandel der Buchwidmung in der Zeit von 1625 bis 1769 vgl. die entsprechende Monographie von Gabriele Schramm. Diese hält als ein wesentliches Element der Widmungspraxis vor allem des 17. Jahrhunderts fest, dass dem (zumeist adligen) Gönner durch die Widmung explizit oder implizit Nachruhm versprochen wird resp. Dichter darauf hoffen, dass potenzielle Gönner „wenigstens die ,Begiehr der Unsterbligkeit‘ in die Mäzenatenrolle treib[t]“ (Schramm 2003, S. 6o2, vgl. u. a. S. 6o1-6o5). 
Universität umgekehrt wesentlich beigetragen hat. Eine mögliche Antwort auf die Frage, weshalb sich Widmungen noch immer halten, wäre also in der Kombination einer langen Paratexttradition einerseits mit dem Zur-SchauStellen und Bekräftigen bürgerlichen Selbstbewusstseins andererseits zu finden. Ein Ansatz für eine weitere Antwort hingegen, eine Antwort, die zum Kern der vorliegenden Arbeit führt, findet sich bereits im alten Ägypten, so etwa in einer Weisheitslehre des 13. Jahrhunderts vor Christus, die mit ihrer vergleichenden Bezugnahme auf die Dauerhaftigkeit des Erzes an den berühmten Vers ${ }^{2}$ des Horaz erinnert: ${ }^{3}$

\author{
Jene weisen Schreiber \\ seit der Zeit, die nach den Göttern kam, \\ die verkündeten, was kommen werde, \\ deren Namen bleiben bestehen in Ewigkeit, \\ obwohl sie dahingegangen sind, \\ nachdem sie ihre Lebensspanne vollendet hatten, \\ und obwohl alle ihre Angehörigen vergessen sind. \\ Sie haben sich keine Pyramiden aus Erz, \\ keine Grabsteine aus Eisen errichtet; \\ Sie konnten auch keine Erben hinterlassen in Gestalt von Kindern, \\ die ihre Namen hätten lebendig erhalten können. \\ Vielmehr haben sie sich Erben geschaffen \\ in Gestalt von Büchern mit Lehren, die sie verfaßt haben. \\ $[\ldots]$ \\ Es wurden ihnen Tore an ihre (Grab-)Hallen gemacht - \\ nun sind sie zerfallen;
}

2 „Exegi monumentum aëre perennius“ / „Errichtet habe ich ein Monument, das Erz überdauert"; die Parallelen sind noch deutlicher, liest man über den ersten Vers der Ode hinaus: „das den majestätischen Bau der Pyramiden überragt, / welches nicht der nagende Regen noch der Nordwind zügellos / vermag zu zerstören oder unzählbar / der Jahre Folge und der Zeiten Flucht" (Horaz, Oden, III, 30 resp. Horaz 2015, S. 182 f.). Aber im Unterschied zu den zitierten altägyptischen Versen wird hier, freilich weitaus impliziter als in Ovids Nachwort der Metamorphosen (siehe unten Kapitel I.4.2), die selbstbewusste Ewigkeitsbehauptung auch reflektiert, hin auf die Abhängigkeit der Ode von Lesern, die der lateinischen Sprache mächtig sind: „Nicht gänzlich werde ich vergehen, ein großer Teil von mir / wird entgehen der Todesgöttin; unaufhörlich werde ich in der Nachwelt / wachsen im Ruhme jugendfrisch, solange auf das Kapitol / steigen wird mit der schweigenden Jungfrau der Priester“ (ebd.). Diese Lesergebundenheit ist geblieben (auch die Übersetzung ins Deutsche ist ein Zeugnis davon), selbst wenn Horaz' Ode das Ende der römischen Kulte und den Dienst der Vestalinnen bereits eineinhalbtausend Jahre überdauert hat.

3 Diese Parallele zu Horaz ist bereits anderen Forschern aufgefallen; vgl. dazu J. Assmann 1991, S. 173, Anm. 1; vgl. dazu ergänzend Börnchen 2006, S. 115-117; dieser verweist auch auf die Pyramidensimilitudo bzw. -metapher im Zusammenhang mit Tod, Grab und (Schrift-) Zeichen bei Hegel und Derrida. 
ihre Totenpriester sind fort, ihre Grabsteine mit Erde bedeckt, ihre Gräber vergessen.

Und doch wird ihr Name genannt, und zwar wegen der Bücher, die sie verfaßt haben, als sie noch lebten.

Gut ist die Erinnerung an ihren Verfasser

bis in alle Ewigkeit. ${ }^{4}$

Noch komprimierter findet sich dieser Ansatz bei Platon, der in seinem Symposion Diotima Folgendes in den Mund gelegt hat:

Und jeder würde sich wünschen, dass ihm eher solche Kinder geboren werden als die leiblichen, indem er voller Bewunderung auf Homer und Hesiod und die anderen vortrefflichen Dichter blickt, was für eigene Nachkommen sie hinterlassen haben, die ihnen unsterblichen Ruhm und ewiges Andenken gewähren, da sie selbst so (unvergänglich) sind. ${ }^{5}$

Nach Diotima wäre eine Dissertation für die Eltern des Autors oder der Autorin also so etwas wie der bessere Enkel, gezeugt von einem schlechteren, lediglich biologischen Kinde. ${ }^{6}$ Und dass diese biologischen Kinder - Schriftsteller, Dichterinnen, Wissenschaftler - Widmungen verfassen, läge nach ihr am Versuch, nicht nur sich, sondern auch seine Eltern mittels Schrift zu verewigen. Potenzielle Gründe für diesen Versuch gäbe es viele: von Dankbarkeit und Liebe und dem Wunsch, die Eltern an der eigenen vermeintlichen Unsterblichkeit teilnehmen zu lassen, über die Freude oder das schlechte Gewissen, ein nach Diotima ,besseres Kind geboren‘ zu haben als die Eltern, bis zu ,schlichtem‘ Pflichtgefühl gegenüber der Familie und/oder den Vorgaben der Textsorte. Damit ist das Feld aufgetan, von wo aus und wie man sich der in der abendländischen Kultur- und Geistesgeschichte seit Jahrtausenden präsenten Vorstellung, Schriftzeichen könnten Vergängliches verewigen, nähern könnte: Die möglichen Herangehensweisen reichen von der Geschichtswissenschaft über die Anthropologie bis hin zur Psychologie.

4 Papyrus Chester Beatty IV, verso 2.5-2.13, zitiert nach Brunner 1988, S. 224 f. Vgl. dazu u. a. Dorn 2009, S. 70-24; J. Assmann 2003, S. 46 f.; und ders. 1991, S. 173-178.

5 Platon, Symposion, S. 117.

$6 \mathrm{Zu}$ altgriechischen Vorstellungen zur Relation der beiden ,Kinder ${ }^{‘}$ mit der Unsterblichkeit ihrer jeweiligen ,Eltern' vgl. Svenbro 2005, S. 65-77. Bemerkenswert ist in diesem Zusammenhang auch die Nähe der lateinischen Wörter librî und lîberî (beide im Plural), wobei ersteres ,Bücher', letzteres ,Kinder‘ bedeuten kann. Da die Römer keine Längenzeichen verwendeten, ist der Unterschied schriftlich noch geringer, ,Bücher und ,Kinder fallen somit in der Schrift beinahe wortwörtlich zusammen. 
All diese unterschiedlichen Disziplinen hätten jedoch ein grundsätzliches Problem auf sprachlich-semiotischer Ebene zu berücksichtigen, das die weltweit frühsten heute bekannten, zum Teil umstrittenen Schriftzeugnisse (ca. 5300 v. Chr.) der sogenannten Donauzivilisation, ${ }^{7}$ auch alteuropäische Zivilisation genannt, ${ }^{8}$ ebenso betrifft wie antike Grabinschriften, heutige an Brücken befestigte Schlösschen mit den Namen resp. Initialen von Verliebten oder die Möglichkeit, einen Facebook-Account in den ,Gedenkzustand' und damit in einen virtuellen Grabstein zu verwandeln. ${ }^{9}$ Dieses Problem ist die Doppelung ${ }^{10}$ eines jeden sprachlichen Zeichens in eine materiale und eine intelligible Konstituente, die Ferdinand de Saussure mit signifiant (Signifikant) und signifié (Signifikat) benannt hat." ${ }^{11}$ Dieser Doppelung - die auch icons und indices und damit letztlich jedem Zeichen inhärent ist - entwächst die Bedingung, dass ein sprachliches Zeichen zu seiner Konstitution immer auf einen Rezipienten angewiesen ist, der die materiale Ebene des Zeichens mit der intelligiblen verbindet, um erst dann über jene intelligible Ebene zum Referenten, dem Gegenstand, auf den das Zeichen verweist, zu gelangen (vgl. ,semiotisches Dreieck ${ }^{c}$ ). Für Schriftzeichen im Speziellen heißt dies also, dass sie auf eine Leserin oder einen Leser ${ }^{12}$ angewiesen sind, wollen sie nicht bloße Kerbe in einem Stein, Druckerschwärze auf einem Blatt Papier, Kontrast auf einem Bildschirm usw. bleiben.

Diese grundsätzliche Lesergebundenheit eines Schriftzeichens resp. die an Rezipienten gebundene intelligible Seite von Zeichen im Allgemeinen ist denn auch bekanntlich die Basis für Zeichenmodelle, die dasjenige Saussures erweitern, indem sie den Kommunikationszusammenhang, in dem ein Zeichen im Zuge seiner Konstitution zwingend steht, miteinzubeziehen suchen. Für die vorliegende Untersuchung genügt es jedoch vorerst, das Modell Saussures jeweils im Hintergrund mitzubedenken. Komplexere Zeichenmodelle werden, wo notwendig, zu gegebener Zeit miteinbezogen, so etwa im Kapitel III

7 Vgl. Haarmann 2011, S. 20; und ders. 1991, S. 69-80.

8 Vgl. Haarmann 1991, S. 7 .

9 Zur „Bedeutung der Virtualität für das Todesproblem“ vgl. Krüger 2004, S. 94-99.

10 Eine solche Dopplung gilt selbst dann, wenn man für eine Kultur wie die altägyptische eine Kultur der „unmittelbaren Signifikation“ annimmt, wo die Weltreferenz von Zeichen zugleich immer auch Gottesreferenz bedeutet haben soll (vgl. J. Assmann 1991, S. 88-90). Eine sehr gute Auseinandersetzung mit Saussures Zeichentheorie im Zusammenhang mit der Schrift unter Einbezug von Derridas Phonozentrismuskritik am Genfer Linguisten, die an wesentlichen Stellen (auch durch inkorrekte bis verfälschte Zitate) ein falsches Bild von Saussures Thesen vermittelt, findet sich bei Stefan Börnchen (vgl. ders. 20o6, S. 162-170).

12 Wenn im Folgenden vom ,Leser oder von ,Lesern` die Rede ist, sind Leserinnen selbstverständlich immer auch mitgemeint. 
zur poetischen Performativität, das einleitend eine Kombination von John L. Austins Sprechakttheorie mit Roman Jakobsons „poetischer Funktion“ vornimmt.

Wenn im Folgenden von ,Schriftzeichen' die Rede ist, so sind damit aufgrund des Fokus auf den abendländischen Kulturraum und wenn nicht explizit von anderen Schriftsystemen die Rede ist - bedeutungstragende Zeichen $^{13}$ der lateinischen Alphabetschrift gemeint; bei Verweisen auf altgriechische, hebräische oder arabische Texte ebenfalls Zeichen der betreffenden Alphabetschriften. Dies heißt jedoch nicht, dass die Erkenntnisse der vorliegenden Arbeit, insbesondere dort, wo sie semiotische Operationen beschreiben, grundsätzlich nicht auf andere Kulturräume und Schriftsysteme übertragbar wären. ${ }^{14}$

Das Problem, das die Dopplung eines jeden sprachlichen Zeichens in eine materiale und eine intelligible Konstituente für die Verewigung mittels Schriftzeichen mit sich bringt, ist bereits auf innersprachlicher Ebene - also selbst wenn man die Vergänglichkeit der Materialität von Schrift und Schriftträger außer Acht lässt - mindestens zweifacher Natur:

Erstens ist - die Kenntnis der Schrift und der verschriftlichten Sprache einmal vorausgesetzt - das Signifikat, das mentale Konzept, das das Zeichen in einem ersten Schritt ,weckt', unter verschiedenen Lesern nie exakt deckungsgleich. Je abstrakter die Semantik des Zeichens, je größer die individuellen, zeitlichen, kulturellen usw. Abweichungen ${ }^{15}$ zwischen dem Leser, seiner

13 Die kleinste Einheit ist dabei oft das einzelne Wort, es kann aber auch ein einzelnes verschriftlichtes Morphem, im Falle von Abkürzungen auch ein einzelner Buchstabe sein. Hinzutreten können, je nach Kontext, auch einzelne Satzzeichen, wie etwa der Gedankenstrich, die ebenfalls bedeutungstragend sein können; vgl. zu Letzterem etwa die Kapitel zu Miss Sara Sampson und den Lebens-Ansichten des Katers Murr. Dass die hier der Untersuchung unterworfenen Zeichen resp. Zeichengebilde bedeutungstragend sein müssen, ist vermeintlich selbsterklärend: Wo kein Inhalt transportiert wird, kann auch nichts dauerhaft festgehalten werden. Die Grenzen sind bei näherer Betrachtung jedoch nicht absolut trennscharf zu ziehen: So ließe sich selbst für einen einzelnen, isolierten Buchstaben der betreffenden Alphabetschriften sagen, er suche einen Lautwert dauerhaft festzuhalten; ein weiteres Problem stellen Schriftimitationen dar, deren Zeichen an sich nichts bedeuten, die in ihrer Verweisfunktion auf Schriftlichkeit, ihrer magischen Aufladung usw. (vgl. z. B. Hiller 2003, S. 36) jedoch durchaus bedeutungstragend sind.

14 Freilich würde eine solche Übertragung aber Ergänzungen (in beide Richtungen) und Einschränkungen mit sich bringen; vgl. dazu den betreffenden Ausblick in Kapitel 2.1 des Schlussteils.

15 Veränderungen, die den Sprachgebrauch einer ganzen Kommunikationsgemeinschaft betreffen, wie etwa Bedeutungswandel, sind dabei ebenfalls mitgemeint. Dass das Bewusstsein darum, dass jedes Wort resp. Morphem einem Bedeutungswandel unterworfen ist, erst im Verlauf des 18. Jahrhunderts entsteht, darauf hat Peter Szondi in seiner 
Lebenswelt und dem einstigen spezifischen Kommunikationszusammenhang des jeweiligen Zeichens, desto größer die Abweichung vom einstigen gedachten Signifikat des Verfassers des Zeichens und desto prekärer der Verweis auf den Referenten. ${ }^{16}$ Dies gilt bekanntlich bereits für eine wiederholte Lektüre der gleichen Schriftzeichen durch dieselbe Person, da deren jeweilige neue Lektüre, von den vorangegangen Lektüren beeinflusst, immer eine andere gewesen sein wird. ${ }^{17}$

Zweitens ist die Wiederholbarkeit der Aktualisation - im Falle der Schriftzeichen die Wiederholbarkeit der Lektüre - die Möglichkeitsbedingung eines jeden Zeichengebrauchs, wie bereits Jacques Derrida treffend festgestellt hat. ${ }^{18}$ Der Verfasser von Schriftzeichen, der zugleich deren erster Leser ist (sofern er nicht bloß im engsten Sinne abschreibt), hat keine Kontrolle mehr über deren Signifikat, sobald er die Zeichen niedergeschrieben hat - und dass eine solche Kontrolle nicht statthaben kann, ermöglicht ihm überhaupt erst den freien Gebrauch der von ihm verwendeten Zeichen usw. ${ }^{19}$

Die Ausgangslange ist also eine paradoxale: Auf der einen Seite findet sich die Vorstellung, Schriftzeichen könnten Gedanken, Dinge oder Personen und deren Taten verewigen. Auf der anderen Seite ist in semiotischer Hinsicht ein Schriftzeichen äußerst flüchtig: Es vermag im Zuge der Lektüre nie zweimal das exakt identische Signifikat zu wecken und wird, kaum gelesen, immer wieder nur noch (z. B.) schwarze Farbe auf weißem Papier gewesen sein; während auf rein biologisch-physikalischer Ebene sowohl der Leser als auch das Schrift- und Schriftträgermaterial - allesamt unabdingbar für die Konstitution von Schriftzeichen - nicht der Zeit enthoben, sondern Tod und Verfall unterworfen sind.

Mit der Feststellung dieses Paradoxons hat sich die Vorstellung, Schriftzeichen könnten Gedanken, Dinge oder Personen und deren Taten verewigen, als semiotisch falsch erwiesen. Konsequenterweise müsste man also eine Auseinandersetzung mit jener Vorstellung bereits hier wieder beenden oder auf eine rein historische Untersuchung des Auftretens derselben ausweichen. Oder aber man bleibt nicht einfach bei der Feststellung des Paradoxons stehen,

Auseinandersetzung mit Johann Martin Chladenius hingewiesen (Szondi 1975, insbesondere S. $76-78)$.

16 Vgl. dazu mit Blick auf die Hermeneutik und die Sehnsucht, in der jeweiligen Kommunikationssituation das ,treffende' Wort zu finden - dabei auf Hans-Georg Gadamer eingehend -, Angehrn 2004, S. 126.

17 Vgl. dazu zusammenfassend ebd., S. 175-177; sowie den Einbezug des Begriffs der Iterabilität in Kapitel 1.1 des Schlussteils.

18 Vgl. Derrida 1999.

19 Vgl. ebd., u. a. S. $346-349$. 
sondern nimmt die intellektuell produktive Irritation an, die ein jedes Paradoxon bereithält. Genau Letzteres tut die vorliegende Arbeit. Und das führt nun - noch ehe ihre genaue Fragestellung zu nennen ist - zu einer ersten, für die Arbeit und das Vorbeugen von Missverständnissen zentralen begrifflichen Differenzierung: Im Folgenden wird nicht mehr von der „Vorstellung, Schriftzeichen könnten Gedanken, Dinge oder Personen und deren Taten verewigen“, die Rede sein, sondern präziser zum einen von der Ewigkeitsbehauptung gegenüber Schriftzeichen und zum anderen von der Ewigkeitsattribuierung von Schriftzeichen.

Mit Ewigkeitsbehauptung gegenüber Schriftzeichen sind jeweils all die Textstellen resp. Aussagen gemeint, die trotz der oben festgestellten Flüchtigkeit behaupten, Schriftzeichen könnten Gedanken, Dinge oder Personen und deren Taten für alle Zeiten festhalten und damit verewigen. Diese Behauptung kann implizit erfolgen oder explizit, die Grenzen sind dabei zum Teil fließend.

Implizite Ewigkeitsbehauptungen gegenüber Schriftzeichen begegnen einem auf Schritt und Tritt und reichen von den oben bereits erwähnten, in unseren Tagen an Brücken und Geländern festgemachten Schlösschen mit den Initialen von Verliebten über Goethes Rede zum Schäkespears Tag (vgl. Kapitel IV.3.3 zur Genieästhetik) bis hin zu Hans-Georg Gadamers Verwendung des „Klassischen“ (vgl. das Kapitel zum Forschungsstand). Implizite Ewigkeitsbehauptungen gegenüber Schriftzeichen müssen nicht zwingend allein auf sprachlicher Ebene erfolgen, oft werden sie auch kombiniert mit Elementen, die nicht direkt mündlichen oder schriftlichen Aussagen zuzuordnen sind, so etwa im Falle der institutionellen und architektonischen Elemente bei Archiven und Bibliotheken. Die vorliegende Arbeit hat sich jedoch auf die sprachliche Ebene zu beschränken.

Explizite Ewigkeitsbehauptungen gegenüber Schriftzeichen sind seltener, aber dennoch ebenfalls zahlreich anzutreffen, so z. B. in Schillers Prolog zu Wallensteins Lager (vgl. Kapitel III.1.2.1), im Zusammenhang mit der Forderung nach Pressefreiheit in Lessings Schrift Die Nachtigall im Ersten Beitrag von Zur Geschichte und Litteratur ${ }^{20}$ oder auch einer fiktiven Figur in den Mund

20 „Was Einmal [sic] gedruckt ist, gehört der ganzen Welt auf ewige Zeiten. Niemand hat das Recht, es zu vertilgen. Wenn er es tut, beleidiget er die Welt unendlich mehr, als sie der Verfasser des vertilgten Buches, von welcher Art es auch immer sei, kann beleidiget haben. Er stürzet sie vorsetzlich [sic] in Ungewissheit und Zweifel; er beraubt sie des einzigen Mittels, selbst zu sehen, selbst zu urteilen; er verlangt, auf eine eben so vermessene als lächerliche Art, dass sie ihm blindlings glauben, ihn blindlings für einen eben so ehrlichen als einsichtsvollen Mann halten soll“ (Lessing, Werke, Bd. 7, S. 449). 
gelegt wie in E. T. A. Hoffmanns Lebens-Ansichten des Katers Murr ${ }^{21}$ - oder etwa, wie bereits zitiert, in altägyptischen Texten, den Worten Diotimas in Platons Symposion und dem berühmten Vers aus Horaz' Ode. Das gilt auch für die ebenfalls schon im antiken Griechenland zu beobachtende umgekehrte Perspektive mit der freilich selben Behauptung: dass das Schreiben von der Sterblichkeit derer zeuge, die schreiben (im Gegensatz zu den griechischen Göttern, die als Unsterbliche das Schreiben nicht nötig haben). ${ }^{22}$ Zumindest bei ambitionierteren Autorinnen und Autoren finden sich in unmittelbarer Nähe von Textstellen mit Ewigkeitsbehauptungen oft auch Textstellen mit Ewigkeitsattribuierungen, was im Laufe des Hauptteils dieser Arbeit immer wieder zu beobachten sein wird.

Ewigkeitsattribuierung von Schriftzeichen bezeichnet die Versuche, in einer schriftlichen Äußerung innersprachliche Operationen zu verwenden, die darauf abzielen, die semiotische Flüchtigkeit von Schriftzeichen auszuschalten und dadurch das Signifikat resp. die Signifikate der jeweiligen schriftlichen Äußerung für alle Zeiten festzuhalten. Die oben festgestellte Flüchtigkeit von Schriftzeichen wird im Falle der Ewigkeitsattribuierung also nicht geleugnet resp. ignoriert wie bei der Ewigkeitsbehauptung, sondern es wird gerade in Auseinandersetzung mit dieser Flüchtigkeit versucht, ihr so weit wie möglich entgegenzuwirken, wofür in gewissen Fällen sogar die Flüchtigkeit selbst in Dienst genommen wird (vgl. Kapitel II.2 zur Unteroperation Unendliches Verstummen).

Im Falle des Begriffs Ewigkeitsattribuierung ist es notwendig, die beiden Bestandteile des Kompositums noch etwas genauer zu definieren: Das Bestimmungswort Ewigkeit wird hier - und das gilt auch für das Kompositum Ewigkeitsbehauptung - verwendet in Anlehnung an die in der Alltagssprache im Kontext von Verschriftlichung gebrauchte Bedeutung des Verbs verewigen. ${ }^{23}$ Es meint ein vom Zeitpunkt des jeweiligen Schreibaktes an end-

21 „Kann aber auch wohl einem hohen Genius jemals unbedeutendes begegnen? Alles, was er in seiner Knabenzeit unternahm oder nicht unternahm, ist von der höchsten Wichtigkeit, und verbreitet helles Licht über den tiefern Sinn, über die eigentliche Tendenz seiner unsterblichen Werke" (Hoffmann, Werke, Bd. ${ }_{5}$, S. 38). Diese Textstelle wird in Kapitel IV.3.3 noch genauer behandelt.

22 Vgl. Svenbro 2005, S. 142, inklusive Anm. 44.

23 „verb. ewig, unsterblich machen, mhd. verêwigen, sehr selten, zusammensetzung zu einfachem ewigen theil 3, 1204, dessen bedeutung ver nicht ändert" (Deutsches Wörterbuch von Jacob und Wilhelm Grimm, Bd. 25, Sp. 284 f.). Zum Verb ,ewigen‘: „perpetuare, perpetuis temporibus possidendum dare, perennem, immortalem reddere, mhd. êwigen“" (ebd., Bd. 3, Sp. 1204-1206). Um 1800 sind, im Gegensatz zu heute, noch beide Formen in Gebrauch, wie die im Deutschen Wörterbuch angeführten Zitate belegen. Das 
loses Fortdauern der verschriftlichten Inhalte resp. der Signifikate in der Zeit. Das Grundwort Attribuierung hingegen betont, dass diese ,Ewigkeit' nicht den Schriftzeichen wesenhaft inhärent ist, sondern ihnen dieses Attribut von außen zugeschrieben ${ }^{24}$ wird.

Freilich besitzt der Begriff Ewigkeit im abendländischen Kulturraum auch eine starke christlich-theologische Konnotation. Was die rein innersprachlichsemiotische Ebene der Versuche zur Ewigkeitsattribuierung von Schriftzeichen anbelangt, so sei dezidiert klargestellt, dass eine solche Konnotation hier nicht mitgemeint ist.

Dass diese Konnotation aber dann, wenn es um eine historische Kontextualisierung der Versuche zur Ewigkeitsattribuierung von Schriftzeichen geht, mitschwingt, ist durchaus erwünscht: Die Attribute des Ewigen und Unsterblichen wurden (und das gilt nicht nur für den abendländischen Kulturraum) über Jahrtausende hinweg den Göttern zugeordnet, schon lange vor der Dominanz des Christentums. Ebenso war der Schriftgebrauch in zahlreichen Kulturen lange Zeit eng mit dem priesterlich-sakralen Bereich verbunden oder diesem gar vorbehalten. So verortet man denn auch die weltweit ältesten bekannten (zum Teil umstrittenen) Schriftzeugnisse der sogenannten Donaukultur ausschließlich im Bereich des Sakralen. ${ }^{25}$ Noch weiter gehend ist mit Harald Haarmanns Universalgeschichte der Schrift festzuhalten:

[D]ie ersten Aufzeichnungen überlieferter Texte in den antiken Kultursprachen sind weder juridische Texte noch Chroniken, und in keiner der regionalen Schrifttraditionen stehen literarische Texte am Anfang. Die Motivationen, eine Schrift zu entwickeln und zu verwenden, sind nirgendwo weltlicher Art oder künstlerischer Natur. ${ }^{26}$

Jasper Svenbro vertritt angesichts des sehr frühen und breiten Auftretens der Alphabetschrift im antiken Griechenland zum Totengedenken die These, dass jene vielleicht ursprünglich eigens zu diesem Zweck aus dem Nahen Osten

Schweizerdeutsche Wörterbuch (Idiotikon), zugleich auch das detailreichste Wörterbuch für das Frühneuhochdeutsche, nennt zum Verb ,ewen' resp. ,êwigen' gar explizit die enge Verknüpfung des Verbes mit der Schrift: „dauerhaft machen (das Andenken durch Schrift)" (Schweizerdeutsches Wörterbuch, Bd., 1, Sp. 608 und 612).

24 ,Zugeschrieben' auch und gerade im wortwörtlichen Sinne.

25 Vgl. Haarmann 1991, S. 73.

26 Ebd., S. 70. 
übernommen wurde. ${ }^{27}$ Dieser archäologisch global ${ }^{28}$ beobachtete Ursprung der Schrift im Bereich des Sakralen scheint auch in zahlreichen mythologischreligiösen Überlieferungen zu den Erfindern der Schrift(en) nachzuwirken: Bei Platon z. B. ist es Theut (Thot), der die ägyptischen Hieroglyphen erfunden hat; bei Isidor von Sevilla ist es die Göttin Isis und für das Hebräische Moses; in gewissen islamisch geprägten Überlieferungen gilt Allah offenbar als ursprünglicher Erfinder der arabischen Schrift, während etwa christliche Legenden von Gott inspirierte Heilige und Missionare als Erfinder der gotischen, kyrillischen, armenischen und georgischen Alphabete betrachten. ${ }^{29}$ Trotz dieses archäologisch verbürgten und mythologisch-religiös aufgeladenen Ursprungs der Schrift ist aber - zumindest für den abendländischen Kulturraum - bis in die heutige Zeit generell folgende Tendenz zu beobachten: die Übertragung des den Göttern vorbehaltenen Attributs der Ewigkeit auf die Schrift, während parallel dazu die Schrift dort, wo sie hauptsächlich dem sakralen Kontext vorbehalten war, aus dem sie einst stammte, immer mehr von diesem unabhängig verwendet wird - eine Tendenz, die sich in der Zeit um 1800 verstärkt und dabei besonders sichtbar wird. ${ }^{30}$ (Näheres dazu folgt im letzten Kapitel der vorliegenden Einführung, das eine historische Problematisierung der Ewigkeitsbehauptungen gegenüber Schriftzeichen vornimmt.) Die Konnotation des verwendeten Begriffsteils Ewigkeits- mit dem Bereich des Sakralen im Allgemeinen und der christlich-jüdischen Theologie im Speziellen ist für die historische Ebene also gewollt und keine Unschärfe, sondern eine Stärke des gewählten Begriffes, der so auch an die geschichtliche Dimension der Versuche zu Ewigkeitsattribuierungen von Schriftzeichen erinnert. Genau diese Versuche und deren historische Kontextualisierung sind es denn auch, die im Zentrum dieser Arbeit stehen.

Dabei werden zwei Leitfragen verfolgt, wobei die erste und stärker gewichtete primär auf semiotischer, die zweite auf historischer Ebene angesiedelt ist:

27 Svenbro 2005, S. 16, 168. Er verweist dabei zudem auf eine in der Forschung selten zitierte Erzählung des Historikers Skamon von Mytilene (4. Jahrhundert v. Chr.), der den Namen für die griechische Alphabetschrift Phoinikeïa tà grámmata nicht von den Phöniziern herleitet, sondern von der frühzeitig verstorbenen Tochter Phoinike des mythischen attischen Erfinders der grámmata, König Aktaion. Hierbei dient also bereits der Name für die Schrift selbst der Verewigung (der verstorbenen Tochter); vgl. ebd., S. 16 f. und 78-82.

28 Als Beispiel hierfür gilt etwa das alte China, wo die Schrift zunächst ausschließlich dem Orakelwesen vorbehalten war (vgl. Haarmann 2003, S. 42).

29 Vgl. Kiening 2016, S. 167 f.; resp. Kiening/Stercken 2008, S. 20.

$30 \quad$ Vgl. dazu auch Nate 2018; Neumann 2018; und Theisohn 2012. Ähnliches ist zumindest im Falle der christlich (zum Teil auch der islamisch) geprägten Kultur ebenfalls für die ,sakrale lyrische‘ Stimme zu beobachten; vgl. Weigel 2006, S. 23-25. 
1. Welche innersprachlichen Operationen sind beim Versuch zu beobachten, die semiotische Flüchtigkeit von Schriftzeichen auszuschalten, um damit die Signifikate der jeweiligen schriftlichen Äußerungen für alle Zeiten festzuhalten und so mittels Schriftzeichen Gedanken, Dinge oder Personen und deren Taten zu verewigen?

Das Ziel der Beantwortung dieser Frage liegt im Erarbeiten einer Typologie dieser innersprachlichen Operationen zur Ewigkeitsattribuierung von Schriftzeichen. Der Begriff Operationen wird hier synonym mit dem in der jüngeren literaturwissenschaftlichen Forschung verwendeten Begriff Verfahren verwendet, ist diesem im Folgenden aber deshalb vorzuziehen, weil mit ihm treffender Komposita wie Grund- und Unteroperation gebildet werden können. Die Arbeit verfolgt nicht den Anspruch, eine umfassende und abschließende Typologie vorzulegen, wohl aber die (zumindest im gewählten Zeitraum um 180o) am häufigsten eingesetzten Operationen zu klassifizieren und zu behandeln. Zudem sei, um jeglichen dahingehenden Missverständnissen vorzubeugen, dezidiert festgehalten, dass hier nicht nach dem Stein der Weisen gesucht, sondern eine Typologie von Versuchen erarbeitet wird - Versuche, die semiotische Flüchtigkeit von Schriftzeichen auszuschalten. Der Begriff Versuche steht dabei nicht für eine jeweils zwingende, bewusste, ohnehin nie gänzlich zu klärende Autorintention; die betreffenden Operationen können ebenso unbewusst zum Einsatz kommen oder - wie der Hauptteil zeigen wird - sich gar verselbstständigen und die Autorintention unterlaufen. ${ }^{31}$,Versuche' soll lediglich betonen, dass die Operationen zur Ewigkeitsattribuierung von Schriftzeichen selbst nach größtem intellektuellem Aufwand aufgrund der oben dargelegten semiotischen Gesetzmäßigkeiten ihr Ziel nie gänzlich erreichen können und damit im Zuge einer Lektüre immer nur Versuche gewesen sein werden. Das verstärkte (bewusste und unbewusste) Anrennen resp. mittels jener Versuche wortwörtliche Anschreiben gegen diese Unmöglichkeit, sich mittels Schriftzeichen der Ewigkeit zu versichern, ist denn auch - so wird sich im Laufe der Arbeit zeigen - eine der zentralen Triebfedern hinter bedeutenden ästhetischen und literarischen Entwicklungen der Zeit um 1800 und vielleicht der Moderne überhaupt.

2. Wie lassen sich diese verfahrensmäßig als Praxis zu fassenden innersprachlichen Operationen zur Ewigkeitsattribuierung von Schriftzeichen in der Zeit zwischen 1755 und 1821 literatur- und geistesgeschichtlich kontextualisieren?

31 Dem allen sucht unten stehende zweite Leitfrage mit der komprimierten Formulierung „die verfahrensmäßig als ,Praxis` zu fassenden innersprachlichen Operationen“ Rechnung zu tragen. 
Hierbei geht es darum, zu beobachten, in welchem Zusammenhang die innersprachlichen ${ }^{32}$ Operationen zur Ewigkeitsattribuierung von Schriftzeichen mit zeitgenössischen geistes- und literaturgeschichtlichen Kon- und Kotexten stehen, sowie festzustellen, ob ein gewisses akzentuiertes Auftreten einzelner solcher Operationen zu erkennen ist und, wenn ja, aus welchen Gründen. Und zugleich geht es auch umgekehrt darum, zu fragen, ob die Versuche der Verewigung mittels Schriftzeichen literatur- und geistesgeschichtliche Entwicklungen und Diskurse mitbestimmt haben und, falls ja, inwiefern.

Aus dieser zweigeteilten Fragestellung ergeben sich die beiden übergeordneten Ziele der gesamten Arbeit: Erstens soll sie mittels eines literaturwissenschaftlich-semiotischen Ansatzes eine Typologie der Operationen zur Ewigkeitsattribuierung von Schriftzeichen erarbeiten, die zwar anhand deutschsprachiger, literarischer Texte um 1800 vorgenommen wird, jedoch den Anspruch erheben darf, eine Grundlage zu bilden für eine allgemeine, über einzelne Sprachen und Schriftsysteme hinausreichende Klassifizierung. ${ }^{33}$ Zweitens versteht sie sich nicht als eine abschließende, geschlossene Beantwortung der oben formulierten Leitfragen, sondern soll mit ihren Ergebnissen und dem Bestreben, Forschungszusammenhänge zu stiften, ein Feld von semiotischen, literaturwissenschaftlichen und geistesgeschichtlichen Anknüpfungspunkten eröffnen. Eine solche Offenheit ist letztlich eine wesentliche Konstituente von Forschung überhaupt, gilt für eine Arbeit wie die vorliegende aber ganz besonders. ${ }^{34}$ Das im Folgenden Erarbeitete möge denn also über die vorliegende Monographie hinaus zu einem besseren Verständnis des Verhältnisses zwischen Schrift und Verewigung, dessen Bedeutung für die Geistes- und Literaturgeschichte um 1800 und des mit ihm verknüpften Anbruchs der Moderne ebenso beitragen wie zur kritischen (Selbst-)Reflexion der philologischen Disziplinen auf eigene, ${ }^{35}$ meist unbewusste Ewigkeitsbehauptungen und -attribuierungen.

32 Inzwischen wurde mehrfach hervorgehoben, dass es sich bei den hier untersuchten Operationen um innersprachliche handelt. Auf das Adjektiv ,innersprachlich' im Zusammenhang mit diesen Operationen wird im Folgenden deshalb verzichtet, um die Begrifflichkeit nicht unnötig ,aufzublasen' und den Lesefluss nicht zu hemmen. Dasselbe gilt in geringerer Häufigkeit auch für die Kürzung oder Weglassung der Formulierung „zur Ewigkeitsattribuierung von Schriftzeichen“, vor allem dann, wenn sich Nennungen kurz nacheinander wiederholen.

33 Mindestens einige dieser Operationen wären auch in anderen Medien zu beobachten; vgl. dazu Kapitel 2.1 des Schlussteils.

34 Eine solche Offenheit ließe sich freilich der Unteroperation Unendliche Lektüre zuordnen; vgl. dazu insbesondere die abschließende kritische Reflexion auf die vorliegende Arbeit am Ende des Ausblicks.

35 Dass ausgerechnet Herders Shakespeare-Aufsatz von 1773, der die (deutschsprachige) moderne Literaturgeschichtsschreibung (mit-)begründet, bereits durchdrungen ist von 


\section{Methode, Eingrenzung des Zeitbereichs, Textauswahl und Gliederung}

Die Beantwortung der ersten der beiden Leitfragen, d. h. das Erarbeiten einer Typologie der innersprachlichen Operationen zur Ewigkeitsattribuierung von Schriftzeichen, erfolgt anhand neun exemplarischer literarischer Texte des deutschen Sprachraums aus der Zeit von 1755 bis 1821. In der Reihenfolge ihrer Behandlung sind dies: Lebens-Ansichten des Katers Murr (Schwerpunkte: Anfang und Ende, Übergänge zwischen Kreisler- und Murr-Biographie), Miss Sara Sampson (Schwerpunkt: Anfang und Ende), Der Spinnerin Nachtlied, Ermunterung, Der Zauberlehrling, Wallenstein (Schwerpunkte: Prolog und Wallensteins Name), Heinrich von Ofterdingen (,Höhlenszene'), Der Phönix und Nänie.

Die verfolgte Methode ist dabei eine dezidiert textnahe. Auch wenn die Lektüren der einzelnen Texte dekonstruktivistisch inspiriert sind, bleiben sie doch immer der auf grundlegendste Weise hermeneutisch geprägten Fragestellung der vorliegenden Arbeit verpflichtet, die auch vor einer kritischen Hinterfragung dekonstruktivistischer Ewigkeitsbehauptungen nicht haltmacht. ${ }^{36}$ Der Verfasser folgt dabei der Überzeugung, dass jene Typologie nur ausgehend von einer akribischen, wo nötig bis in den Mikrobereich der Satzzeichen reichenden analytischen Lektüre der Texte selbst erarbeitet werden kann. Dies hat einen einfachen Grund: Würde sich der Verfasser nicht einem solch dezidiert textnahen Vorgehen verpflichten, liefe er höchste Gefahr, selbst bloße Ewigkeitsbehauptungen von außen an die Texte heranzutragen.

Eine reflektierte textnahe Methode sieht sich einerseits grundsätzlich keiner Autorintention verpflichtet, andererseits hat sie dafür Sorge zu tragen, dass nicht der Anschein einer Ontologisierung der Texte erweckt wird - insbesondere bei einer Fragestellung wie der vorliegenden. Die jüngere Literaturwissenschaft hat sich eine Reihe von Begriffen zugelegt, die zumindest eine Abgrenzung von der Autorintention signalisieren, so etwa: stellt aus, verhandelt, thematisiert, gibt zu lesen und figuriert. Schnell wird dabei das Dilemma ersichtlich, dass die genannten Verben bei aller reflektierten Distanznahme noch immer ein Subjekt benötigen, will man sie in einem grammatisch korrekten Satz verwenden; bei allen ist dies ,der Text' resp. ,die Textstelle', ,der Vers' usw. Freilich kann ein Text im engeren Sinne weder verhandeln, ausstellen, etwas geben etc. noch überhaupt in irgendeiner Weise aktiv handeln. Er wird immer nur geschrieben resp. gelesen worden sein - wobei derjenige, der schreibt,

Ewigkeitsbehauptungen und -Attribuierungen gegenüber/von Schriftzeichen, ist dafür bezeichnend; vgl. dazu Kapitel IV.3.3. 
vorausgesetzt, er schreibt nicht nur im engsten Sinne ab, immer auch der erste Leser ist. Aus praktisch-heuristischen Gründen lässt sich dieser Umstand in einer literaturwissenschaftlichen Arbeit jedoch nicht jedes Mal erneut in aller Breite ausführen, weshalb jene Begrifflichkeit auch hier Verwendung finden soll. Die betreffenden Verben werden im Folgenden insbesondere dann gebraucht, wenn davon die Rede ist, dass ein Text auf eine Weise gelesen werden kann, die ihn nicht nur auf außersprachliche Referenten, sondern auch auf die eigenen innersprachlichen Bedingungen und Möglichkeiten verweisen lässt. Die Möglichkeitsbedingungen für eine solche Lesart wiederum werden zwar einerseits vom Text (mit-)vorgegeben, müssen aber andererseits vom Leser und von dessen Fragestellungen an den Text aktualisiert werden. Ein Verhältnis zwischen Text und Leser, das etwa zur paradoxalen Situation führen kann, dass im Zuge intertextueller Verfahren nicht nur die Lektüre des in seiner Niederschrift früheren Textes den späteren, auf diesen verweisenden, beeinflusst, sondern umgekehrt auch die Lektüre des späteren die des früheren. ${ }^{37}$ Ein Verhältnis, das allein schon wegen der Vergänglichkeit des Lesers jede Verewigung mittels Schriftzeichen resp. mittels Zeichen im Allgemeinen verunmöglicht; ein Verhältnis aber, das mit seinen Paradoxa noch immer Rätsel aufgibt, die als philologische und sprachphilosophische Probleme mittels unseres sprachlich bestimmten Denkens wohl nie gänzlich gelöst werden können. Es bleibt jedoch die Aufgabe, Bedingungen und Möglichkeiten dieses Verhältnisses und seiner Paradoxa - und darunter sind die Versuche der Ewigkeitsattribuierung von Schriftzeichen nicht die unbedeutendsten - weiter zu erforschen.

Dass der Fokus überwiegend auf literarischen Texten liegt, ist darin begründet, dass Literatur der ,Ort' ist, an dem am ausgiebigsten mit den Möglichkeiten und Grenzen von Sprache und Schriftzeichen experimentiert wird - zumal in einer Zeit, in der die modernen philologischen Disziplinen erst im Entstehen begriffen sind. Dies trifft bekanntlich im deutschen Sprachraum ganz besonders für die Zeit um $1800 \mathrm{zu}$ (inklusive literarisch geäußerter Bestrebungen, diese Experimentierfreudigkeit wieder einzudämmen), ${ }^{38}$ was neben den unten angeführten Gründen ein weiteres Kriterium dafür ist, dass sich die Arbeit auf diesen Zeitbereich konzentriert. Bildlich gesprochen werden hier also die einzelnen literarischen Texte als ein Experiment mit Sprache im Allgemeinen und Schriftzeichen im Speziellen betrachtet, wobei versucht wird, aus der genauen Analyse dieser Experimente neue Erkenntnisse über Möglichkeiten und Grenzen von Schriftzeichen im Allgemeinen zu gewinnen. Der Hauptteil der Arbeit ist dabei jedoch so gehalten, dass er

37 Vgl. Frey 199o, S. 8.

38 Vgl. dazu etwa das Kapitel III.1.1 zu Goethes Zauberlehrling. 
die behandelten exemplarischen Texte nicht nur als Grundlage für die zu erarbeitende Typologie verwendet, sondern immer auch einen wesentlichen Beitrag zur Gesamtinterpretation und (literatur-)historischen Bedeutung der einzelnen Texte leistet. Was die zweite der beiden Leitfragen und deren Beantwortung anbelangt, so wird einerseits ebenfalls induktiv mit einzelnen theoretischen Texten und Stellen weiterer literarischer Texte aus dem untersuchten Zeitbereich gearbeitet und andererseits einschlägige Forschungsliteratur der letzten Jahrzehnte hinzugezogen, die wesentlich zu einer breit abgestützten historischen Kontextualisierung von mit dem vorliegenden Gegenstand verwandten Gegenständen und Diskursen beigetragen hat. Beides wird, jeweils verknüpft mit den Befunden aus der Analyse der literarischen Beispieltexte, entsprechend weitergedacht und ergänzt.

Die vorliegende Untersuchung ist absichtlich in einem Zeitbereich angesiedelt, für den die Forschung schon seit Längerem eine diskursgeschichtliche Akzentuierung der Thematisierung von Ewigkeit, Vergänglichkeit und (industrieller) Reproduzierbarkeit, aber auch der Fragen nach Bedingungen und Möglichkeiten des menschlichen Verstehens festgestellt hat. ${ }^{39}$ Einige prominente, zum Teil bereits oben erwähnte Beispiele für diese historische Akzentuierung sind: 1) auf geistesgeschichtlicher Ebene die u. a. von Descartes ausgehende, in der Zeit um 1800 ihren Höhepunkt erreichende Reflexionsphilosophie; der Beginn der modernen literarischen Hermeneutik u. a. mit Schleiermacher; und die fortschreitende Säkularisierung, welche die Bibel, die Heilige Schrift, ihrer Heiligkeit und ewigen Gültigkeit beraubt und gleichzeitig zu einem gewissen Kompensationsreflex führt, der (u. a. anknüpfend an ältere humanistische Ewigkeitsbehauptungen gegenüber Schriftzeichen ${ }^{40}$ dazu tendiert, die Schrift an sich und insbesondere die Dichtung zu etwas Heiligem, Ewigem zu verklären; 2) in literaturgeschichtlicher Hinsicht eine nicht zu übersehende Zunahme der Auseinandersetzung mit Fragen der Zeit und Zeitlichkeit im Allgemeinen ${ }^{41}$ sowie der Problematik des Anfangs und Endes eines Werkes im Speziellen; zu Letzterem wären zu nennen: Gotthold Ephraim Lessing, der das vermeintliche Ende der Tragödie in ein Enden überführt, die Fragmentästhetik der Romantik, ineinander verschachtelte Paratexte, die den Anfang verwischen (z. B. bei Jean Paul und E. T. A. Hoffmann),

$39 \mathrm{Zu}$ den Belegen hierfür vgl. vor allem weiter unten die Auseinandersetzung mit dem Forschungsstand, das Unterkapitel zur historischen Problematisierung der Ewigkeitsbehauptung gegenüber Schriftzeichen zum Schluss dieser Einführung sowie dann natürlich die historisch-kontextualisierenden Kapitel des Hauptteils.

40 Vgl. A. Assmann 1999, S. 116-145; und hinsichtlich der englischen Literaturgeschichte auch Nate 2018, insbesondere S. 259 f., 262, 269 f.

41 Vgl. etwa Göttsche 2001. 
und Rahmenhandlungen (z. B. in Goethes Unterhaltungen deutscher Ausgewanderten), die nicht mehr geschlossen werden; 3) auf sozial- und wirtschaftsgeschichtlicher Ebene der Alphabetisierungsschub im Verlauf des 18. Jahrhunderts ${ }^{42}$ die epochalen, ebenfalls die Bibel durch Dichtung verdrängenden Veränderungen im Schulwesen ${ }^{43}$ neue industrielle Möglichkeiten der Vervielfältigung von Text (Erfindung der Papiermaschine 1799, der Schnelldruckpresse 1811) und der parallel dazu ausgetragene Streit um die Urheberrechte an gedruckten Texten (vgl. z. B. Fichtes Beweis der Unrechtmäßigkeit des Büchernachdrucks) ${ }^{44}$ - historische Veränderungen, die dann wiederum auch literarisch thematisiert werden (z. B. in Hoffmanns Lebens-Ansichten des Katers Murr).

Es ist also zum einen zu erwarten, dass eine Auseinandersetzung mit literarischen Texten aus der Zeit von 1755 bis 1821 besonders aufschlussreiche Ergebnisse zur Ewigkeitsattribuierung von Schriftzeichen liefern wird, zum anderen möchte der Verfasser jene bisherigen, auf topologisch-semantischer sowie zeitphilosophischer und theologischer Ebene für die Zeit um 1800 erfolgten Forschungen noch stärker um die problemgeschichtliche Situierung auf semiologischer, textkonstituierender Ebene ergänzen. Die historischen Kapitel der vorliegenden Arbeit sehen sich denn auch als Beitrag zu einer solchen Ergänzung.

Für die Begrenzung des gewählten Zeitraums stehen zwei der im Hauptteil ausführlich behandelten exemplarischen Texte: Lessings Miss Sara Sampson (1755) und E. T. A. Hoffmanns Lebens-Ansichten des Katers Murr (1819/1821). Wie bereits im Falle der Auseinandersetzung mit Widmungen zu Beginn dieser Einführung ein erstes Mal sichtbar wurde, scheint die zunehmende Herausbildung des Bürgertums einhergehend mit dessen politischen, kulturellen und wirtschaftlichen Konstitutions- und Emanzipationsbestrebungen eine wesentliche Ursache für die soeben genannte Akzentuierung zu sein. Lessings Miss Sara Sampson - dessen Untertitel in der Erstausgabe nicht umsonst ein „Bürgerliches Trauerspiel, in fünf Aufzügen“ lautete ${ }^{45}$ - ist einerseits mit der

42 Vgl. u. a. die Forschungen von Albrecht Koschorke, ders. 1994, S. 605-628.

43 Um 18 oo vollzieht sich zunehmend der Wechsel (in Preußen z. B. ab 1794) weg von einem von der Kirche hin zu einem vom Staat kontrollierten Unterricht, der „Kaplane [...] durch staatsbeamtete Gymnasiallehrer und die Bibel als Elementarbuch alteuropäischer Alphabetisierung durch poetische Fibeln" ersetzt (Kittler 1986, S. 500).

44 Vgl. z. B. Genz 2009, S. 27-41.

45 Kursive Hervorhebung durch MG; zur Editionsgeschichte des Untertitels vgl. Kapitel II.1.2. 
Etablierung der Subgattung des bürgerlichen Trauerspiels und andererseits mit der damit verbundenen Ästhetik des Mitleid(en)s diskursgeschichtlich wesentlich an der kulturellen und ethischen bürgerlichen Identitätsbildung im deutschen Sprachraum beteiligt. E. T. A. Hoffmanns Lebens-Ansichten des Katers Murr nebst fragmentarischer Biographie des Kapellmeisters Johannes Kreisler in zufälligen Makulaturblättern wiederum desavouiert 65 Jahre später ironisch-satirisch den Bürger als oberflächlichen (Bildungs-)Philister, dem der Roman das Bild des wahren Künstlertums Johannes Kreislers gegenüberstellt. Der Bürger erscheint so bei Hoffmann bereits als ein klischeehaft verfügbarer Typus, den es in seiner Erstarrung schon wieder zu überwinden gilt, womit der Roman Lebens-Ansichten des Katers Murr den vorangegangenen Prozess der (kulturellen) Konstitution eines Bürgertums implizit als abgeschlossen markiert.

Jeder und jede der neun ausgewählten exemplarischen Texte resp. Textstellen - im Folgenden auch Textbeispiele genannt - hatte im Auswahlprozess drei grundlegende Kriterien zu erfüllen, um für eine ausführliche Untersuchung im Hauptteil infrage zu kommen:

1) Es muss sich als grundlegendste Voraussetzung herausstellen, dass in ihm mindestens eine Operation zur Ewigkeitsattribuierung von Schriftzeichen zu beobachten ist.

2) Eine jener Operationen zur Ewigkeitsattribuierung von Schriftzeichen muss in dem Textbeispiel eine zentrale Stellung einnehmen, einen ästhetischen Kern des Textes bilden - auch gegenüber anderen, möglicherweise parallel auftretenden Operationen. Je stärker diese einen solchen ästhetischen Kern bildet, desto größer auch die Exemplarität, die der entsprechende Text für eine Untersuchung der jeweiligen Operation einzunehmen vermag. Nimmt eine der Operationen eine zentrale Stellung im untersuchten Text resp. in der untersuchten Textstelle ein, so ist zudem auch die Wahrscheinlichkeit sehr hoch, dass dort die Operation nicht nur auftritt, sondern zugleich auch autoreflexiv thematisiert wird, was wiederum sowohl das Erkenntnispotenzial als auch die Exemplarität des Textbeispiels erhöht. Das heißt aber, dass ebenso die Wahrscheinlichkeit hoch ist, dass alle untersuchten Textbeispiele auch die Unteroperation Autoreflexivität beinhalten. Um Missverständnissen vorzubeugen, seien deshalb die ersten beiden Kriterien für die Textauswahl gleich anhand dieser Unteroperation durchgespielt: Damit ein Textbeispiel Exemplarität für die Unteroperation Autoreflexivität beanspruchen kann, muss es erstens und selbstredend die Unteroperation Autoreflexivität aufweisen, was, freilich in unterschiedlichem Maße, auch für die anderen exemplarischen Textbeispiele zutrifft. Aber zusätzlich muss die Unteroperation Autoreflexivität gemäß 
Kriterium 2 im betreffenden Text auch eine zentrale Stellung einnehmen. ${ }^{46}$ Die exemplarische Textstelle, die in diesem Fall für die vorliegende Arbeit ausgewählt wurde, ist die Höhlenszene in Novalis' Heinrich von Ofterdingen.

3) Die Textbeispiele müssen auch auf ihrer semantischen/inhaltlichen Ebene und/oder im Rahmen des zeitgenössischen kulturellen und theoretischen Kontextes explizit oder implizit das Paradigma von Dauer, Vergänglichkeit, Ewigkeit und/oder Verewigung aufweisen. Dieses Kriterium dient dazu, sicherzugehen, dass im jeweiligen Textbeispiel die betreffende Operation entscheidend der Ewigkeitsattribuierung von Schriftzeichen dient und nicht etwa vorwiegend zu einem anderen Zweck eingesetzt wird, etwa zur ,bloßen Verfremdung des Mitgeteilten, zur reinen Spannungserzeugung etc. Die Übergänge sind dabei freilich graduell, nicht in jedem Fall klar abzugrenzen und wie bei letztlich jedem Zeichengebilde - auch von den Leserinnen und Lesern abhängig. Wenn im Folgenden auf besonders klare Fälle zurückgegriffen wird, so heißt dies also nicht, dass der Verfasser sich einer gewissen heuristisch bedingten Künstlichkeit dieser Grenzziehung nicht bewusst wäre. Vielmehr vermögen die so erlangten Ergebnisse die Perspektive auch umzudrehen: Dass sich gewisse Operationen zur Ewigkeitsattribuierung von Schriftzeichen im Speziellen mit einzelnen Konstituenten von Literarizität im Allgemeinen überschneiden, liegt vielleicht daran, dass die Ewigkeitsattribuierung von Schriftzeichen möglicherweise eine der grundlegendsten Konstituenten von Literarizität ausmacht. Im Extremfall wäre dann etwa Autoreflexivität als ,bloßes' Mittel zur Verfremdung eine abgeleitete (schwache) Form der grundlegenden Literarizitätskonstituente Ewigkeitsattribuierung und nicht umgekehrt - auf diese Möglichkeit ist im letzten Kapitel des Schlussteils noch einmal zurückzukommen.

Neben den drei genannten Kriterien wurde zudem darauf geachtet, dass bei der Wahl der exemplarischen Texte und Textausschnitte die prominentesten Gattungen des Zeitraums von 1755 bis 1821 ausgewogen vertreten sind: Drama (zweimal), Fabel (einmal), lyrisches Gedicht (dreimal), Ballade (einmal) und Roman (zweimal); was einer Auswahl von drei epischen, drei lyrischen und zwei dramatischen Texten sowie einer Ballade, die Episches, Dramatisches und Lyrisches vereint, entspricht. Ebenso zu berücksichtigen war, dass die Texte aus unterschiedlichen Federn stammen; so finden sich unter den neun ausgewählten Texten sieben verschiedene Autoren. Diese Texte werden vor allem in den historisch-kontextualisierenden Kapiteln ergänzt durch die

46 Dass dabei aus Letzterem die autoreflexive Thematisierung der Unteroperation Autoreflexivität als solcher erwächst, liegt dann auch an der Eigendynamik der Grundoperation Reflexivität, der sie angehört; vgl. Kapitel IV. 
Auseinandersetzung mit weiteren theoretischen und literarischen Schriften des gewählten Zeitraumes, u. a. von Herder und Friedrich Schlegel, oder durch einen Exkurs zu Jean Paul und dessen Hesperus. Es sei hier zudem noch einmal erwähnt, dass die vorliegende Monographie die in ihr untersuchten Beispieltexte nicht nur als Grundlage für die zu erarbeitende Typologie verwendet, sondern immer auch einen wesentlichen Beitrag zur Gesamtinterpretation und literaturgeschichtlichen Verortung der einzelnen Texte anstrebt. Es zeigt sich dabei, dass der Blick auf die Operationen zur Ewigkeitsattribuierung von Schriftzeichen oft auch neue Ansätze in der Auseinandersetzung mit den jeweiligen Texten sowie Diskursen eröffnet, die bestehende Forschungsarbeiten ergänzen und miteinander verknüpfen.

Der Hauptteil ist in drei Großkapitel gegliedert, die den drei wichtigsten Grundoperationen zur Ewigkeitsattribuierung von Schriftzeichen gewidmet sind. Die Kapitel A und C zur Unendlichen Aktualisation resp. zur Reflexivität beinhalten jeweils ein größeres Unterkapitel, das sich eigens der historischen Kontextualisierung der entsprechenden Operationen in der Zeit um 1800 widmet. Im Falle der in Kapitel III behandelten Grundoperation Autonome Performative Produktion wird $u$. a. aufgrund von Überschneidungen mit den beiden anderen historisch-kontextualisierenden Kapiteln und einer ausführlicheren Berücksichtigung des zeitgenössischen Kontextes direkt bei der Behandlung der einzelnen Textbeispiele auf ein eigenes historisches Kapitel verzichtet. Genauere Definitionen der Grundoperationen sowie der dazugehörigen Unteroperationen finden sich zu Beginn der betreffenden (Unter-)Kapitel. Auch wird den meisten Kapiteln, seien es die historischkontextualisierenden oder diejenigen zu den Beispieltexten, eine Aufarbeitung des jeweils spezifischen Forschungsstandes vorangestellt. ${ }^{47}$ Letzteres mag bei einer durchgehenden Lektüre des Buches vielleicht mit der Zeit etwas schematisch wirken; da das Lesen wissenschaftlicher Monographien aber in der Praxis oft nicht linear erfolgt, wurde eine solche klare Binnenstruktur letztlich als für die Mehrheit der Leserschaft orientierungsfreundlicher erachtet.

Der Schlussteil besteht aus zwei Unterkapiteln: Das erste führt die Ergebnisse des Hauptteils zusammen und schärft sie da, wo es nötig ist; das zweite greift als Ausblick die wichtigsten Anknüpfungspunkte auf, die sich aus dem Hauptteil für weitere Forschungen anbieten, und bettet dabei zugleich die Ergebnisse des Hauptteils weiter in bestehende Forschungsdiskurse ein. Der

47 Diesbezüglich ließe sich auch für die vorliegende Arbeit die (unbeabsichtigt eingesetzte) Unteroperation Reflexivität beobachten, da die Stuktur der Einzelteile der Arbeit jeweils bis zu einem gewissen Grad die Struktur der ganzen Monographie spiegelt, mit dem Ziel, dadurch autonomer verständlich zu sein ... 
Ausblick hat also eine öffnende und durch diese weitere Einbettung zugleich rahmende Funktion, die sich auf unten stehendes Kapitel zum Forschungsstand rückbezieht.

\section{Forschungsstand}

Eine Aufarbeitung des Forschungsstandes steht im Fall der vorliegenden Arbeit vor der Herausforderung, dass sich auf der einen Seite keine Forschung findet, die sich im engeren Sinne systematisch mit Operationen zur Ewigkeitsattribuierung von Schriftzeichen befasst, auf der anderen Seite aber die Forschungsliteratur, die in irgendeinem Sinne Zeit, Ewigkeit oder Unendlichkeit direkt oder indirekt berühren würde, nahezu uferlos ist. ${ }^{48}$ Dieser Herausforderung wird hier beschränkend begegnet, indem - nach einer grundlegenden Positionierung der Arbeit innerhalb der hermeneutischposthermeneutischen Tradition - anhand von Publikationen der letzten Jahrzehnte bloß ein repräsentatives Bild derjenigen Forschungsarbeiten skizziert sei, die nach bestem Wissen des Verfassers am nächsten an eine systematische Untersuchung von Ewigkeitsattribuierungen von Schriftzeichen heranreichen und/oder zu denen sich umgekehrt die vorliegende Arbeit als grundlegenden, ergänzenden Beitrag versteht. Diese Skizze konstituiert sich aus einer Auswahl, die in drei Teile gegliedert ist: Ein Teil widmet sich der semantisch-historischen Ebene sowie interdisziplinären Ansätzen einer Auseinandersetzung mit Ewigkeit und Unendlichkeit; der darauf folgende Teil befasst sich mit der semiotischen Ebene, spezifisch ausgerichtet auf die Informations- und Wissensvermittlung über lange Zeiträume hinweg; und schließlich folgt eine repräsentative Auswahl von Einzelstudien aus den Literatur- und Kulturwissenschaften sowie der Archäologie, die in ihre grundlegenden kulturgeschichtlichen und kultursemiotischen Forschungen ebenfalls literarische Texte miteinbeziehen und damit auch in der Art und Weise ihres Vorgehens mit der vorliegenden Arbeit verwandt sind.

Die Forschungsliteratur aber, die spezifisch für die einzelnen Textbeispiele und die historisch-kontextualisierenden Kapitel berücksichtigt wurde, ist, um unnötige Wiederholungen zu vermeiden, nicht hier, sondern jeweils direkt im die Einführung abschließenden Unterkapitel zur historischen Problematisierung der Ewigkeitsbehauptungen und in den Kapiteln des Hauptteils eingearbeitet. Gerade die zitierte Forschungsliteratur in den

48 Vgl. zu Letzterem auch Göttsche 2001, insbesondere S. 36. 
historisch-kontextualisierenden Kapiteln ergänzt die hier angeführten Studien entscheidend um Arbeiten zum 18. und frühen 19. Jahrhundert.

\section{Hermeneutik - Posthermeneutik: Ewigkeitsbehauptung gegenüber} Schriftzeichen als Axiom der hermeneutischen Tradition

Als Erstes sei auf die hermeneutisch-posthermeneutische Tradition im Zusammenhang mit Ewigkeitsbehauptungen und -attribuierungen von Schriftzeichen eingegangen. Allein dazu ließe sich eine eigene Arbeit verfassen, weshalb es hier lediglich darum gehen kann, einige für den betreffenden Problemhorizont zentrale Stellen zu umreißen und die vorliegende Arbeit in Bezug auf diese Tradition zu verorten.

Friedrich Schleiermacher, der nach der neueren Forschung zwar nicht mehr als der Begründer, aber doch als wirkmächtigster Vertreter einer modernen, universellen Hermeneutik gilt, ${ }^{49}$ nimmt in seiner Vorlesung Das Leben Jesu (1832) eine gewisse, freilich theologisch eingeschränkte Historisierung von Person, Leben und Wirken Jesu Christi vor. ${ }^{50}$ Zugleich geht er jedoch als gläubiger Christ von der Prämisse aus, dass bei Jesus „ein[] Einfluss seiner Wirksamkeit[,] und zwar ein[] über alle Völker und über alle Zeitalter sich erstreckende[r]“,,51 gedacht werden könne. Damit findet sich Schleiermacher im Paradoxon wieder zwischen der Historisierung Jesu zum einen und der Ewigkeitsbehauptung gegenüber dessen Leben, Taten und Wirksamkeit zum anderen. Schleiermachers Vorlesung ist dabei im Grunde einer doppelten Hermeneutik verpflichtet: einerseits dem Verständnis des damaligen Wirkens Jesu und andererseits dem Verständnis dieses überlieferten Wirkens für die eigene Gegenwart des 18. resp. 19. Jahrhunderts. Da das Verständnis beider aber auf den schriftlichen Texten beruht, die von Jesus berichten, hat sich Schleiermacher letztlich nicht nur mit der Ewigkeitsbehauptung gegenüber dem Wirken Jesu, sondern eben zugleich auch mit der Ewigkeitsbehauptung gegenüber den Evangelien auseinanderzusetzen. Nicht zufällig verweist er denn auch auf die Sprache Jesu (und damit implizit auf die Schriften, die von dessen Worten berichten), die als Sprache grundsätzlich dem außersprachlichen Kontext und der Zeit unterworfen sei:

49 Vgl. etwa den (von Gadamer verfassten) Eintrag „Hermeneutik“ in: Historisches Wörterbuch der Philosophie, Bd. 3, Sp. 1064; oder Reinhard 2013, u. a. S. 19 f. und 22. Zur Wirkmächtigkeit Schleiermachers und zur Berichtigung der neueren Forschung, dass er nicht als alleiniger Begründer der modernen Hermeneutik bezeichnet werden könne; vgl. u. a. überblickshaft Böhl 2013, S. 24O; oder bereits Szondi 1975, S. 135 ff.

$50 \quad$ Vgl. auch Frank 1977, S. 33 f.

51 Schleiermacher, Leben Jesu, S. 392. 
[S]o konnte sich Christus nicht anders als in der Sprache ausdrücken [sic] die ihm angeboren und anerzogen war, und auf der seine Gemeinschaft mit anderen Menschen beruhte; und fragen wir: trug diese die absolute Gotteserkenntnis in sich, oder das Vermögen, diese im Einzelnen adäquat zum Bewußtsein zu bringen? so sagen wir nein! denn sonst wäre Christus gar nicht nötig gewesen, sondern die Gotteserkenntnis hätte sich von selbst mittelst der Sprache weiter verbreitet; und also in dieser Beziehung der Sprache, in dem sinn-/lichen Ausdrucke seiner Gotteserkenntnis stand er unter der Potenz, seiner Volkstümlichkeit, deren Ausdruck die Sprache, und allerdings auch seines Zeitalters: und wenn er eine Wirksamkeit ausüben sollte in dieser Beziehung, so konnte er es nur mittelst der gangbaren Vorstellungen, deren er sich bedienen mußte. ${ }^{52}$

Nicht die Sprache selbst ist es also, die die Gotteserkenntnis beinhaltet habe, sondern Christus, der seine Gotteserkenntnis aber mittels Sprache den Menschen seiner Zeit vermitteln musste. Schleiermacher stößt hier somit zwar auf jenes der Ewigkeitsbehauptung gegenüber Schriftzeichen inhärente Paradoxon, kann es aber noch - trotz seiner in anderen Schriften angestrebten Entwicklung einer allgemeinen Hermeneutik, die apodiktische zeitgenössische Setzungen wie z. B. den interindividuelles Verstehen ermöglichenden ,gemeinsamen Geist' infrage stellte ${ }^{53}$ - mit dem Verweis auf den Glauben an Gott (und implizit dessen Ewigkeit) sowie das Göttliche in Jesus Christus wenn vielleicht nicht lösen, so doch zumindest im Falle der Heiligen Schrift stehen lassen.

Erste Ergebnisse des Kapitels zur Genieästhetik (vgl. IV.3.3) vorwegnehmend, ist hier daran zu erinnern, dass Johann Gottfried Herder in seinem Shakespeare-Aufsatz (1773) und damit bereits knapp 6o Jahre vor Schleiermachers Vorlesung die Historisierung des Genies vornimmt - und sich sogleich in demselben Paradoxon wiederfindet. Herder aber, der sich mit Menschen und deren Werken befasst, kann dieses nicht wie Schleiermacher über den christlichen Glauben an die ewige Wirkmächtigkeit Gottes umgehen, hält aber - man ist versucht zu sagen: gerade deswegen - implizit an einem Glauben an die ewige Wirkmächtigkeit der Texte des Genies fest. Als wichtigen Vorläufer Schleiermachers, der mit seinen Überlegungen zur Hermeneutik „die Äußerste Ausdehnung der transzendentalen Wende auf den Bereich der Signifikanten überhaupt ${ }^{\text {“54 }}$ wesentlich begründet, müsste man also nicht nur

52 Ebd., S. 393 .

53 Vgl. Frank 1977, S. 22 f., der hier auf Friedrich Asts Lehrbuch Grundlinien der Grammatik, Hermeneutik und Kritik (1808) verweist.

54 Ebd., S. 8. 
etwa Friedrich Schlegel hervorheben, ${ }^{55}$ sondern eventuell stärker als bisher auch Johann Gottfried Herder. ${ }^{56}$

Schleiermachers postum herausgegebenes ,Hauptwerk' Hermeneutik und Kritik, mit besonderer Beziehung auf das Neue Testament (1838) entwirft aber bekanntlich bereits eine universelle Hermeneutik, ${ }^{57}$ die 1.) der Möglichkeit, Äußerungen vollends zu verstehen, zumindest nach Manfred Frank gar kritischer begegnet als später Wilhelm Dilthey oder Hans-Georg Gadamer ${ }^{58}$ und die 2.) nicht - wie noch im Falle des Verstehens der Heiligen Schrift durch eine Verstehensgarantie Gottes abgesichert ist.

$\mathrm{Zu} \mathrm{1.)}$ Ob Manfred Franks Einschätzung letztlich zutrifft oder nicht, sei hier dahingestellt. Für den Gegenstand der vorliegenden Arbeit interessanter ist, dass er dabei auf Schleiermachers Überlegungen hinweist, die sich mit der Beziehung der eigenen Gedanken auf die zu verstehenden Gedanken eines anderen auseinandersetzen. ${ }^{59}$ In Schleiermachers Hermeneutik und Kritik heißt es dazu:

Die Beziehung der Gedanken eines andern auf die eigenen liegt, sofern sie hermeneutischer Art ist, ganz auf der Seite der grammatischen Interpretation. Hier ist sie notwendig, denn in der grammatischen Interpretation liegt die Beziehung zwischen den Gedanken eines andern und den meinigen als Ort der Sprache. Wenn aber eben die Aufgabe ist, die Gedanken eines andern als seine Produktion vollkommen zu verstehen, müssen wir uns von uns selber los machen. ${ }^{60}$

Objektive Deckungsgleichheit der Gedanken von Sender und Empfänger ist nach Schleiermacher also allein möglich auf der Ebene des überindividuellen Systems der Sprache, deren grundlegende grammatische Strukturen für alle gleichermaßen verbindlich sind. ${ }^{61}$ Für die vorliegende Arbeit und ihre Fragestellung - resp. als erste Bestätigung ihres Fokus und ihrer Methodik - mag Schleiermacher damit einen ersten Ansatzpunkt bereithalten, hieße dies doch, dass innersprachliche Operationen, die eine Unabhängigkeit des Kommunizierten von zeitlichen Veränderungen und außersprachlichem Kontext anstreben, besonders auf "die Seite der grammatischen Interpretation“

\footnotetext{
55 Vgl. ebd.; und Historisches Wörterbuch der Philosophie, B. 3, Sp. 1064.

56 Vgl. dazu auch Frank 1977, S. 10.

57 Vgl. etwa Böhl 2013, S. 239.

58 Auch wenn Dilthey und Gadamer selbst dies zum Teil anders sahen: vgl. Frank 1977,

S. $46-52$, insbesondere S. 46 f. und 52 .

59 Ebd., S. 52 f.

6o Schleiermacher, Hermeneutik und Kritik, S. 213.

61 Vgl. auch Böhl 2013, S. 238 f.
} 
abzielen müssten. Bezeichnenderweise hat auch Peter Szondi in seiner kleinen Schrift Bemerkungen zur Forschungslage der literarischen Hermeneutik (1970) bereits das Potenzial dieser "Seite der grammatischen Interpretation“ für die (literarische) Hermeneutik ausblickshaft betont: „Dabei finden sich in Schleiermachers Theorie der grammatischen Interpretation Einsichten, welche nicht nur Theoreme der modernen Linguistik vorwegnehmen, sondern auch der Anwendung der Linguistik auf die literarische Hermeneutik den Weg weisen.“62

$\mathrm{Zu}$ 2.) Schon bei Schleiermacher zeigt sich also die Übertragung der transzendentalen Wende auf die Hermeneutik ${ }^{63}$ resp. auch innerhalb derselben die Wende weg von der Dominanz der theologisch-exegetischen Hermeneutik im Sinne einer Lehre des Verstehens der Heiligen Schrift hin zu einer Disziplin des Verstehens von Texten im Allgemeinen und den Möglichkeitsbedingungen des Verstehens überhaupt. ${ }^{64}$ Diese Ausweitung deckt sich mit dem schon weiter oben vorausgreifend erwähnten Befund, dass in der Zeit um 1800 die zunehmende Abwendung von der Heiligen Schrift zu einer Heiligung der Schrift als solcher führt. Damit fällt aber auch die ewige Wirksamkeit Jesu resp. Gottes, die bei Schleiermacher die ewige Wirksamkeit der heiligen Texte selbst dann noch garantiert, wenn diese Texte historisch betrachtet und in die eigene Gegenwart übersetzt werden, weg. Trotzdem bringen es später sowohl Dilthey als auch Gadamer (wie schon Herder vor ihnen) offensichtlich nicht über sich, die Ewigkeitsbehauptung gegenüber Schriftzeichen explizit und mit aller Konsequenz als das zu behandeln, was sie ist: eine bloße Behauptung. Stattdessen bedienen sie sich gerade dort, wo es um die grundsätzlichsten Möglichkeitsbedingungen einer Hermeneutik ginge, letztlich apodiktischer Setzungen: Man findet nun „das Allgemeinmenschliche“65 in Diltheys Aufbau der geschichtlichen Welt in den Geisteswissenschaften (1910) und „das Klassische“66 in Gadamers Wahrheit und Methode (1960), die anstelle des ewigen Wirkens Gottes „über alle Völker und über alle Zeitalter"67 verstehbar bleiben sollen. Damit tragen letztlich weder Dilthey noch Gadamer

62 Szondi 1975, S. 406.

63 Vgl. Frank 1977, S. 9 f.

64 Vgl. Böhl 2013, S. 239.

65 Dilthey 1981, insbesondere S. 262-267.

66 Gadamer 199o, vor allem S. 293-295. Zum römischen Begriff der classici und der antiken Kanonbildung ausgehend von Alexandria und den dort praktizierten hermeneutischen Verfahren vgl. Böhl 2013, S. 34 f.; und J. Assmann 2005, S. 277-28o, insbesondere Anm. 36. Zur Geschichte des Klassischen als Teil einer "Strategie der Dauer“ (und der Kritik daran) als Erfindung der Humanisten vgl. A. Assmann 1999, S. 116-136.

67 Schleiermacher, Leben Jesu, S. 392. 
zu einer grundsätzlichen Auseinandersetzung mit der Ewigkeitsbehauptung gegenüber Schriftzeichen bei, sondern verstärken diese noch weiter.

Bei Gadamer findet sich jedoch auch eine Stelle, in der er "das Klassische“ in Anlehnung an Hegel als das beschreibt, "was sich bewahrt, weil es sich selber bedeutet und sich selber deutet" ${ }^{68}$ Eine solche Definition des Klassischen besitzt Ähnlichkeiten mit einer Grundoperation der Ewigkeitsattribuierung von Schriftzeichen, nämlich derjenigen der Reflexivität und insbesondere der Unteroperation der Poetologie (vgl. Kapitel IV). Hier fände sich also ein Ansatz zu einer Infragestellung der Ewigkeitsbehauptung gegenüber Schriftzeichen, ein Ansatz, der jedoch von Gadamer weder als solcher erkannt noch weiter ausgeführt wird.

Selbst die Posthermeneutik unternimmt keinen Versuch, Ewigkeitsbehauptungen gegenüber Schriftzeichen und/oder Ewigkeitsattribuierungen von Schriftzeichen systematisch zu untersuchen. Und dies, obwohl ihr Interesse an zeichentheoretischen Fragestellungen und innersprachlichen Verfahren wie etwa Performativität oder Autoreflexivität besonders groß ist Verfahren, die auch zur Ewigkeitsattribuierung von Schriftzeichen eingesetzt werden können. So trugen denn Jacques Derrida sowie die schriftzentrierte Dekonstruktion überhaupt indirekt - trotz oder gerade wegen ihres Insistierens auf einer unendlichen Verschiebung des Sinns im Zuge der Semiose - ebenfalls zu einer Stärkung der Ewigkeitsbehauptung gegenüber Schriftzeichen bei. ${ }^{69}$ Dasselbe gilt letztlich auch für den sogenannten Iconic Turn. ${ }^{70}$

Als für die vorliegende Arbeit direkt relevantes Beispiel hierzu sei kurz Derridas Aufsatz resp. Vortrag Signature, Événement, Contexte (1971) aufgegriffen, dessen Befunde die semiotische Flüchtigkeit von Sprachzeichen umreißen. Zu diesen Befunden gehören u. a.: Der Kontext zeichenhafter Äußerungen ist nicht absolut, Zeichen sind nicht an ihn gebunden und können potenziell unendlich oft in einen neuen Kontext gestellt werden; die potenziell unendliche Iterierbarkeit resp. genauer: Iterabilität ist die Bedingung sowohl für schriftliche als auch für mündlich geäußerte Zeichen und selbst bei performativen Sprechakten deren Möglichkeitsbedingung; die

68 Gadamer 1990, S. 294.

69 Mehr dazu im Kapitel zur historischen Problematisierung der Ewigkeitsbehauptungen gegenüber Schriftzeichen. Als Überblick zur Kritik an Derridas Logozentrismuskritik vgl. u. a. Weigel 2006, S. 16-22; Wiethölter 2008, S. 10 f. und 25 f.; dazu auch Svenbro 2005, S. 190; und Kiening/Stercken 2008, S. 17 .

70 Vgl. Kolesch/Krämer 2006, S. 8, wo es u. a. heißt: „Die,Wende zum Bild“ beerbt eine auf den Sehsinn zentrierte Tradition, welche im impliziten Skriptizismus der sprachkritischen Wende nicht etwa abbricht, vielmehr in veränderter Form gestärkt und fortgesetzt wird.“ 
Quelle einer sprachlichen Äußerung ist in der Äußerung selbst nie präsent. ${ }^{71}$ Bezeichnenderweise findet sich dann im Aufsatz auch folgender Gedanke zu einem weiterführenden „Projekt“:

Es ist weniger nötig, das Zitieren oder die Iteration [frz. itération, MG] der NichtIteration eines Ereignisses entgegenzusetzen, als vielmehr eine differentielle Typologie von Iterationsformen zu konstruieren, gesetzt, dieses Projekt ist durchführbar und kann Anlaß zu einem erschöpfenden Programm geben, eine Frage, die ich hier beiseite lege. ${ }^{72}$

Man könnte sagen, die vorliegende Arbeit, die eine Typologie derjenigen innersprachlichen Operationen zu erarbeiten gedenkt, die zur Ewigkeitsattribuierung von Schriftzeichen eingesetzt werden, geht in die Richtung eines solchen, an dieser Stelle von Derrida angedachten, aber nicht weiterverfolgten „Projekt[es]““. ${ }^{73}$ Dabei sieht sich die Arbeit aber nicht als Ablehnung der hermeneutischen Tradition, sondern als Beitrag zu einer kritischen ${ }^{74}$ Ergänzung derselben. Auf bereits bestehende Ansätze zu einer solchen kritischen Ergänzung u. a. von Karlheinz Stierle, Jürgen Bolten, Emil Angehrn und Daniel

71 Vgl. Derrida 1999.

72 Ebd., S. 346. Der Vollständigkeit halber sei hier erwähnt, dass Derrida in Richtung différance zielend fortfährt: „In dieser Typologie wird die Kategorie der Intention nicht verschwinden, sie wird ihren Platz haben, aber von diesem Platz aus wird sie nicht mehr den ganzen Schauplatz und das ganze System der Äußerung beherrschen können. Vor allem hat man es dann mit verschiedenen Arten von iterierbaren Zeichen (marques) und Zeichenketten zu tun, und nicht mit einer Opposition von zitathaften Äußerungen einerseits, von einzelnen und einzigartigen Äußerungen-Ereignissen andererseits.“

73 Michel Foucaults Überlegungen zur „Duplikation“/„Doppelung“ in seiner Schrift Le langage à l'infini (1963; dt. Titel: Die Sprache, unendlich resp. Das unendliche Sprechen) berühren zudem ebenfalls Derridas spätere Projektidee bezüglich einer „Typologie von Iterationsformen“ (vgl. Foucault 2003). Die ausführliche Auseinandersetzung mit diesen Überlegungen Foucaults und dann vor allem auch Maurice Blanchots, der in diesem Zusammenhang sowohl bei Derrida als auch Foucault im Hintergrund mitzudenken wäre, würde mit dem Bezug auf den ,realen“ Tod das semiologische „Projekt“ Derridas resp. die vorliegende Arbeit mit ihrem semiologischen und historischen Fokus um eine anthropologische Dimension ergänzen. Dieser Herausforderung müsste man sich wohl bei einer breiten und konsequenten Weiterverfolgung der Befunde der vorliegenden Arbeit dereinst stellen (in Zustimmung oder Ablehnung); der Verfasser würde dabei aber zu höchster Vorsicht mahnen, da die Gefahr einer Ontologisierung von Zeichen bei einem solchen Unterfangen besonders hoch ist, bereits in Foucaults Aufsatz auftritt und deshalb in einem ersten Schritt schon nur bezüglich dieses Aufsatzes zu problematisieren wäre. Für den Hinweis auf Das unendliche Sprechen sei Rüdiger Campe gedankt.

74 ,Kritisch` auch und gerade im Sinne der kantischen Bedeutung von Kritik um 1800 als einer vernunftbasieren Überprüfung seiner selbst und der eigenen Verfahren. 
Müller Nielaba sowie auf den Begriff der Iterabilität wird in den Kapiteln 1.1 und 2.2 des Schlussteils zurückgekommen.

Die kurzen Ausführungen haben darauf hingewiesen, dass sowohl die Literaturwissenschaft (vgl. Herder) als auch die moderne Hermeneutik (vgl. Schleiermacher) sich bereits in ihrer Geburtsstunde mit dem Paradoxon der semiotischen Flüchtigkeit von (Schrift-)Zeichen einerseits und den zugleich mit ihnen verbundenen Ewigkeitsbehauptungen andererseits konfrontiert sahen, wobei sich eine implizite Bejahung der Letzteren durchsetzte. Noch mehr: Mit der vorliegenden Arbeit drängt sich gar die freilich etwas pointierte Hypothese auf (vgl. dazu das letzte Kapitel des Schlussteils), dass sowohl die Literaturwissenschaft als auch die Hermeneutik in ihrer modernen Form ausgehend von der zweiten Hälfte des 18. Jahrhunderts überhaupt erst aus der intellektuellen Auseinandersetzung mit jenem Paradoxon entstanden sind. Dies ist vielleicht auch der Hauptgrund dafür, dass Ewigkeitsbehauptungen gegenüber Schriftzeichen bis heute auch und gerade in diesen Disziplinen sowohl implizit als auch explizit omnipräsent sind, aber nie systematisch untersucht wurden - stellt eine Untersuchung derselben in gewissem Sinne doch auch ursprüngliche, zum Teil bis heute prägende Prämissen der eigenen Disziplinen infrage. Der Verfasser ist jedoch der Überzeugung, dass eine solche Untersuchung das Fundament der betreffenden Disziplinen letztlich nicht schwächt, sondern vielmehr zu stärken vermag.

\subsection{Studien zu Eigenzeiten sowie Unendlichkeit und Ewigkeit}

Betreffend Studien, die sich weniger auf semiotischer als vielmehr semantisch-historischer Ebene mit Zeit und Ewigkeit befassen und dennoch in die Nähe einer Untersuchung von Ewigkeitsattribuierungen von Schriftzeichen gelangen, ist hier vor allem das 2013 in Angriff genommene DFGSchwerpunktprogramm 1688 „Ästhetische Eigenzeiten, Zeit und Darstellung in der polychronen Moderne" zu erwähnen. Es umfasst in zwei Förderphasen (seit 2013 resp. 2016) insgesamt 29 Teilprojekte und „bezieht sich in seinem leitenden Forschungsinteresse auf das Verhältnis von Zeit und Darstellung“. Es untersucht

[a]n einer großen Vielfalt von Phänomenen und einem weiten Spektrum beteiligter Disziplinen [...], wie Zeitlichkeit in ihrer kulturellen und historischen Vieldeutigkeit in der Form ,ästhetischer Eigenzeiten` erfahrbar gemacht und reflektiert wird. ${ }^{75}$ 
Die Leitparadigmen sollen Zeitdarstellung und Zeit-Wissen, nicht Zeiterfahrung und Ästhetische Wahrnehmung bilden; die Ausrichtung soll in der beschriebenen Weise kulturwissenschaftlich und wissensgeschichtlich sein $[\ldots]{ }^{76}$

Der Begriff „Ästhetische Eigenzeiten“ wird dabei wie folgt definiert:

Ästhetische Eigenzeiten werden als exponierte und wahrnehmbare Formen komplexer Zeitgestaltung, -modellierung und -reflexion verstanden, wie sie einzelnen Gegenständen bzw. Subjekt-Ding-Konstellationen eigen sind. Dies ist bei Kunstwerken unterschiedlicher medialer und materialer Provenienz in hohem Maße der Fall, trifft aber auch in vergleichbarer Weise für andere Artefakte und Objekte der materiellen Dingkultur zu, bei denen komplexe, auf vielen Ebenen zugleich stattfindende (Selbst-)Bezüglichkeiten in der Beobachtung zur Wahrnehmung idiosynkratischer Zeitlichkeiten führen. [...] Eigenzeitlich sind diese Objekte deshalb nicht aus sich selbst heraus, vielmehr sind sie eigenzeitlich, weil sie sich, ob affirmativ oder negierend, in eigensinniger Weise auf Prozesse der Synchronisierung beziehen. Die globalen Tendenzen einer Relationierung aller Zeitordnungen sind zugleich die Voraussetzung und der Motor von Eigenzeiten. ${ }^{77}$

Hierbei werden Unterschiede und Gemeinsamkeiten bezüglich der vorliegenden Arbeit ersichtlich: Das DFG-Schwerpunktprogramm „Ästhetische Eigenzeiten“ (und letztlich ebenso die umfangreiche Arbeit Dirk Göttsches) ${ }^{78}$ fokussiert auf Darstellungen von Zeit und Zeitlichkeit und auf die - mit der im 18. Jahrhundert u. a. von Herder und Kant ausgehenden Relativierung von Zeit verknüpften ${ }^{79}$ - Entstehung einer „Vielheit moderner Zeitlichkeiten“.80 Also genau auf Aspekte, die in gewissem Sinne der vorliegenden Untersuchung gegenläufig sind. Zudem liegen die Untersuchungsgegenstände des Schwerpunktprogramms, von wenigen Ausnahmen abgesehen, allesamt in der Zeitspanne vom 19. Jahrhundert bis in die Gegenwart. Andererseits lässt sich aber der geistes- und kulturgeschichtliche Prozess einer Verzeitlichung durchaus in Verbindung bringen mit in der Zeit um 1800 akzentuiert auftretenden Bemühungen, ebendieser Verzeitlichung mittels Operationen zur Ewigkeitsattribuierung entgegenzuwirken - was aber letztlich den Prozess der Verzeitlichung nur noch weiter antreibt. Insofern mögen die parallel entstandenen Untersuchungen des DFG-Schwerpunktprogramms und der vorliegenden Arbeit sich sowohl hinsichtlich ihrer Gegenstände als auch der

76 http://www.aesthetische-eigenzeiten.de/konzept/\#forslage [Stand: Juni 2018].

77 Gamper und Hühn 2014, S. 23 f.

78 Göttsche 2001 .

79 Gamper und Hühn 2014, S. 27-37.

8o Ebd., S. 21. 
fokussierten Zeitspanne gegenseitig ergänzen. Im Kapitel 2.1 des Schlussteils wird deshalb auch als Ausblick noch einmal hierauf zurückgekommen. Letzteres gilt auch für Michael Theunissens Negative Theologie der Zeit, ${ }^{81}$ die mit ihrer philosophisch-theologischen Auseinandersetzung mit Zeit(en), Zeitlichkeit und Ewigkeit(en) einen für die Fragestellungen der vorliegenden Arbeit zu allgemeinen Ansatz verfolgt, über sie hinaus jedoch zahlreiche Anknüpfungspunkte bietet.

Ergänzend wäre es interessant, zu wissen, wie sich bezüglich historischer Linien des Diskurses zu Zeit und Ewigkeit dereinst das DFG-Schwerpunktprogramm zu Bruno Hillebrands Monographie Ästhetik des Augenblicks (Göttingen 1999) stellt. Der Untertitel Der Dichter als Überwinder der Zeit - von Goethe bis heute weckt allerdings (gelesen vor dem Hintergrund der Suche nach Operationen zur Ewigkeitsattribuierung von Schriftzeichen) etwas falsche Erwartungen. Generell ist man geneigt, viele der Beobachtungen Hillebrands im Grunde zu teilen, während einen die oft plakativ gehaltenen Schlussfolgerungen zuweilen jedoch kritisch stimmen. Zu Letzterem trägt auch der explizit genannte Umstand bei, dass das Buch „essayistisch konzipiert" sei und deshalb „kein Anlass [besteht, MG], akribisch alle Zitate zu belegen“ ${ }^{82}$ Für die Zeit um 1800 stellen sowohl Hillebrand als auch die historischen Kapitel der vorliegenden Arbeit ein akzentuiertes, mit dem Diskurs des Schöpferischen ${ }^{83}$ verbundenes und wirkmächtiges literarisches Ringen mit und um Ewigkeit fest. Hillebrands Thesen hingegen, „[d]ie Ewigkeit mußte komprimiert werden im Augenblick“84 und "[d]er Augenblick war die letzte Möglichkeit, den Saum des Mantels Ewigkeit zu haschen“, ${ }^{85}$ hält der Verfasser im Falle ersterer für zu ungenau, im Falle letzterer in dieser Absolutheit schlicht für falsch. Auch bei der These, dass Goethe, Schiller oder die Romantiker den Verlust der (christlichen) Ewigkeit nicht beklagt hätten, ${ }^{86}$ kann hier so nicht mitgegangen werden.

In den letzten 15 Jahren sind im deutschen Sprachraum zudem vier Sammelbände ${ }^{87}$ erschienen, die Modelle von Ewigkeit, Unendlichkeit und den damit zusammenhängenden Konzepten von Einheit und Vielheit aus

\footnotetext{
$81 \quad$ Vgl. Theunissen 1991.

82 Hillebrand 1999, S. 148.

83 Vgl. ebd., u. a. S. 12.

84 Ebd., S. 10.

85 Ebd., S. 147.

86 Vgl. ebd., S. 9.

87 Reinke 2004; Brachtendorf/Möllenbeck/Nickel 2008; Brachtendorf/Herzberg 2011. Böttigheimer/Dausner 2018. Zu nennen wären etwa des Weiteren mit historischem Ansatz: Lenz 2013; und Eire 2010.
} 
verschiedensten Disziplinen zusammentragen, um „den Problemhorizont [dieses Themas, MG] etwas erkennbar werden zu lassen und das Gespräch [zu] fördern“88 und um - ausgehend von der Feststellung, dass „, [h] öchst unterschiedliche Konzepte von Unendlichkeit [...] in der Geistesgeschichte und in den verschiedenen Disziplinen [kursieren] “89 - Fragen wie den folgenden nachzugehen:

In welchem Verhältnis stehen Unendlichkeit, Unermesslichkeit, Maßlosigkeit, Anfangs- und Endlosigkeit, Kontinuum, Grenzenlosigkeit, Vollkommenheit oder Ewigkeit zueinander? Worin besteht die Pointe der unterschiedlichen Bedeutungsnuancen von Unendlichkeiten dies- und jenseits verschiedener Wissenschaften? [...] Gibt es am Ende eine über die simple Äquivokation hinausgehende allgemeine Bedeutung der Unendlichkeit jenseits der Fächergrenzen, so dass diese als ein faszinierendes Denkbild besonderer Art fungieren kann? ${ }^{90}$

Nach semiologischen oder literaturwissenschaftlichen Beiträgen sucht man in den ersten drei dieser vier Sammelbände jedoch vergeblich. Dies ist insofern besonders bedauerlich, als die gesichteten Beiträge immer wieder an sprachliche Grenzen stoßen, die jedoch oft nicht als solche weitere Behandlung finden. Einige Beispiele hierfür seien kurz genannt. Edgar Forschbach konstatiert: „Seit 197 o beschäftigt man sich [in der Mathematik, MG] überdies mit so genannten hyperunendlichen Mengen. Das sind Mengen, die die unendlichen Mengen umfassen, sie sind nicht mehr konstruierbar, nur begrifflich erfassbar. ${ }^{411}$ Hier könnte sich die Sprach- und Literaturwissenschaft ergänzend einbringen und auf die sprachliche Figuration von Einheiten resp. Ganzheiten mittels Begriffen, denen aber nach Derrida selbst wiederum eine potenziell unendliche Verweisstruktur inhärent ist, hinweisen. Dasselbe gilt, wenn der Philosoph Colin McGinn enthusiastisch davon spricht, dass mittels des Wortes ,Ewigkeit' in der Zeit auf etwas verwiesen wird, das wir letztlich nicht erfassen können, ${ }^{92}$ oder wenn Thomas Görnitz aus Sicht der Physik anmerkt, dass es „für alle Physiker [...] heute selbstverständlich [ist], den Kosmos in seiner Frühphase als Ganzen quantenphysikalisch zu beschreiben“. ${ }^{93}$ Gerald Hartung setzt sich seitens der Philosophie und Anthropologie in seinem Aufsatz Unendlichkeit oder Maßlosigkeit? Anthropologische Überlegungen u. a. mit Nietzsche, Dilthey und Cassirer sowie dem Diskurs der „doppelten

\footnotetext{
88 Reinke 2004, S. 7 .

89 Brachtendorf 2008, S. VI f.

$90 \quad$ Ebd., S. VII.

91 Forschbach 2004, S. 53 .

92 McGinn 2004, S. 94.

93 Görnitz 2004, S. 77.
} 
Unendlichkeit" auseinander ${ }^{94}$ - jedoch ohne die in diesem Zusammenhang prominenten zeichentheoretischen Überlegungen Cassirers (etwa die begriffliche Beschränkung des Einzelnen zwecks Eingliederung desselben in ein Ganzes) miteinzubeziehen..$^{95}$ Johannes Brachtendorf und Stephan Herzberg listen in ihrer Einführung zum Sammelband Einheit und Vielheit als metaphysisches Problem Paradoxa und logische Probleme auf, die sich bei der Auseinandersetzung mit Fragen nach Einheit und Vielheit ergeben ${ }^{96}$ - aber auch hier vermisst man eine angemessene Berücksichtigung sprach- und zeichentheoretischer Ansätze. ${ }^{97}$

Wenngleich sich die vorliegende Arbeit auf die Erarbeitung einer Typologie von Operationen zur Ewigkeitsattribuierung von Schriftzeichen und deren historische Kontextualisierung beschränkt, mag sie vielleicht trotzdem mithelfen, sich seitens der Philologien noch mehr an diesem Diskurs zu beteiligen. Dabei unterstützt sie auch die Ergebnisse des jüngsten und vierten der Sammelbände: Unendlichkeit, Transdisziplinäre Annäherungen, der als erster Band einer dereinst dreiteiligen Reihe 2018 erschienen ist und auch literaturgeschichtliche Beiträge beinhaltet. Denn die Leithypothese der Reihe, dass der Begriff der Unendlichkeit "als eine europäische Kulturkonstante nachweisbar“ sei, sowie den „ideengeschichtlich höchst bemerkenswert[en]“ Befund, „dass der Rekurs auf das Unendliche eine seit Beginn der Neuzeit vorfindliche und nachweisbare Persistenz aufweist" ${ }^{98}$ bestätigt auch die vorliegende Arbeit. Während also die angekündigten zwei weiteren Bände mit Spannung erwartet werden dürfen, ist hinsichtlich der literatur- und geistesgeschichtlichen Teile der vorliegenden Monographie besonders der Beitrag von Richard Nate hervorzuheben: Nate verweist nämlich in Bezug auf die englische Literaturgeschichte vom 17. bis in das frühe 20. Jahrhundert darauf, dass „Vorstellungen von Unendlichkeit, die traditionell dem Bereich des Göttlichen vorbehalten waren, im Zuge eines allgemeinen Säkularisierungsprozesses auf irdische Phänomene übertragen und mit Ideologien individueller und kollektiver Selbsterlösung verknüpft werden“.99 In eine ähnliche Richtung gehen

94 „Pointiert gesagt: Aus der Einsicht in die unendliche Vielfalt des Seienden folgt [im Laufe des 19. und zu Beginn des 20 Jahrhundert, MG] der Gedanke, dass dieses Seiende einer unendlichen Vielzahl von Deutungen zugänglich ist“" (Hartung 2008, S. 118).

Vgl. Cassirer 2001, hierzu insbesondere S. 42 f.: „Das Einzelne als solches wird scheinbar beschränkt; aber eben damit vollzieht sich umso bestimmter und kräftiger jene Leistung, die wir als Integration zum Ganzen bezeichnet haben."

$96 \quad$ Vgl. Brachtendorf 2011, S. 3 f.

97 Vgl. auch Brachtendorf 2008, S. IX.

98 Böttigheimer/Dausner 2018, S. 5 .

99 Ebd., S. 15; vgl. zudem Nate 2018, insbesondere S. 259 f., 262, 269 f. 
Ergebnisse von Yvonne Nilges zu Thomas Mann im selben Sammelband. ${ }^{100}$ Das sprachlich-logische Paradoxon eines Nachdenkens über Unendlichkeit bringt zudem Markus Rothhaar sehr anschaulich auf den Punkt. ${ }^{101}$ Auf seinen Aufsatz wird später noch im Zusammenhang mit Kant und Hegel verwiesen, ebenso wie hinsichtlich eines möglichen historisch akzentuierten Auftretens einzelner Operationen zur Ewigkeitsattribuierung auf Michael Neumanns Beitrag zurückzukommen ist, der ausgehend von der Genieästhetik bis zur Avantgarde des 20. Jahrhunderts „einen radikalisierten Unendlichkeitsbegriff“"102 beobachtet.

\subsection{Aktuelle praktische Herausforderungen des langfristigen Wissenserhalts - am Beispiel der RK\&M-Initiative der OECD}

Aus einer ganz anderen Richtung kommend weist ein vermeintlich fremder Problemkomplex Überschneidungspunkte mit den Fragestellungen der vorliegenden Arbeit auf: Die Rede ist von praktischen institutionellen und unternehmerischen Herausforderungen, jeweils für zentral erachtete Wissensbestände für kommende Generationen zugänglich und verständlich zu halten; Herausforderungen, die im Informationszeitalter trotz neuer technischer Möglichkeiten eher größer als kleiner zu werden scheinen.

Als ein besonders erwähnenswertes Beispiel für solche Herausforderungen mag die Aufgabe unseres Jahrhunderts gelten, sichere Lagerungsorte für radioaktive Abfälle zu schaffen. Aufgrund der Zehntausenden von Jahren, die der Zerfall mancher radioaktiver Materialien in Anspruch nehmen wird, ist die Lagerung der betreffenden Abfälle nicht nur eine naturwissenschaftlichtechnische Herausforderung, sondern, ganzheitlich betrachtet, mindestens ebenso eine semiologische. Denn alle technischen Sicherheitsvorkehrungen, wie sie etwa für geologische Tiefenlager geplant sind, werden letztlich unterlaufen, wenn künftige Generationen aus Unwissenheit fahrlässig mit den betreffenden Lagern umgehen, deren Schutz zerstören, die darin gelagerten Materialien unsachgemäß handhaben usw. Deshalb haben Nationen und

\footnotetext{
100 Vgl. Nilges 2018, insbesondere S. $254 \mathrm{f}$.

101 Vgl. Rothhaar 2018, S. 162-164, insbesondere S. 167, wo er schreibt: „Es ist aber sicherlich hinreichend klar geworden, dass das Begriffspaar Unendlichkeit/Endlichkeit eine herausragende Form der reflexiven Selbstnegation einer Begriffskonstellation darstellt: Das Unendliche, das im Gegensatz zum Endlichen gedacht wird [Hervorhebung MG], erweist sich als das Gegenteil seiner selbst, als Endliches. Damit hebt es sich in einer reflexiven Wendung gegen sich selbst auf und wird zu einem Endlichen. Das Endliche wiederum, das in einem Gegensatz zum Unendlichen verstanden wird, hebt sich auf, da es als isoliertEndliches [sic] in sich selbst negativ ist."

102 Böttigheimer/Dausner 2018, S. 14.
} 
Organisationen, die sich aufgrund ihrer Nutzung von Kernenergie am stärksten mit der Frage nach der sicheren Lagerung radioaktiver Abfälle konfrontiert sehen, 2011 auf Ebene der OECD (resp. deren Nuclear Energy Agency, NEA) die Initiative zur Preservation of Records, Knowledge and Memory across Generations, kurz RK\&M, ins Leben gerufen. Diese versteht resp. verstand sich als Plattform dafür, sich auf internationaler Ebene über Strategien auszutauschen, welche die Weitergabe des Wissens um Radioaktivität, die Standorte der (geplanten) Lager und die darin aufbewahrten Abfälle an kommende Generationen so weit wie möglich sicherstellen sollen. ${ }^{103}$ Vor dem Hintergrund der vorliegenden Arbeit sind dabei drei Punkte hervorzuheben:

Erstens ist festzustellen, dass im gesamten betreffenden Diskurs der Bereich der Literatur bislang weitgehend ausgeklammert wird. Einerseits ist dies insofern erstaunlich, als gerade und insbesondere die Literatur bereits seit Jahrtausenden mit Fragen des Überdauerns des von ihr Festgehaltenen experimentiert. Damit scheint, in der Terminologie des naturwissenschaftlich geprägten Umfelds jenes Diskurses gesprochen, ausgerechnet ein enormer, bereits bestehender Daten-Pool völlig vergessen worden zu sein. Andererseits ist dies erst einmal weder den bisherigen nationalen Bestrebungen noch etwa der RK\&M-Initiative vorzuwerfen - wäre doch die Literaturwissenschaft selbst gefordert, sich dahingehend direkt einzubringen. ${ }^{104}$ Faszinierenderweise findet sich aber im betreffenden Diskurs an exponierter Stelle ausgerechnet eine Ewigkeitsbehauptung gegenüber der Literatur, und zwar in einer Aussage im Schlusskommentar der 2014 in Verdun abgehaltenen, von der Nuclear Energy Agency der OECD mitorganisierten Constructing Memory Conference:

We believe that in order to make further progress we need to go beyond the institutional, professional world and cross into the human world of daily local life. Messages of more than 5000 years old on cuneiform tablets that give us recipes for a stew or register complaints of a weary father about his lazy son are immediately clear to us. Ovid's love poems or the Shakespeare sonnets need no lengthy explanation. Try that with a chemistry treatise a few hundred years old. In contrast with the experiences of daily life that have a universal meaning over

103 Vgl. die betreffende Website: www.oecd-nea.org/rwm/rkm.

104 Erste dahingehende Versuche hat der Verfasser inzwischen erfolgreich unternommen und steht hinsichtlich konkreter Anwendungen der Ergebnisse der vorliegenden Arbeit in Kontakt mit betreffenden nationalen Behörden und Mitgliedern der RK\&M-Initiative; vgl. dazu auch die am 4. September 2019 in Zürich stattgefunden habende Konferenz „Markieren, hinweisen oder vergessen?", organisiert vom Schweizerischen Bundesamt für Energie (https://energeiaplus.com/2019/og/o5/markieren-hinweisen-oder-vergessen [Stand: 05.09.2019]). 
time and space, scientific information and professional practices are very context specific. ${ }^{105}$

Es geht hier nicht darum, diese - gemessen am philologischen, geschichtswissenschaftlichen und hermeneutischen Forschungsstand doch etwas kühne Aussage zu kritisieren, sondern erneut darauf hinzuweisen, wie tief verankert die Ewigkeitsbehauptung gegenüber Schriftzeichen und insbesondere gegenüber der Literatur in der abendländischen Kultur ist. ${ }^{106}$ Derart tief, dass selbst im Rahmen einer Konferenz, für die das Problem der Unbeständigkeit zeichenhaft vermittelter Inhalte die Ausgangslage bildete, im abschließenden, schriftlichen Kommentar die Dauerhaftigkeit genialer' literarischer Werke nicht hinterfragt, sondern erneut in aller Explizitheit behauptet wird. Dabei findet man sich in inhaltlicher und struktureller Hinsicht auf fast schon unheimliche Weise in bester Gesellschaft wieder: in derjenigen Gottfried Herders, der in seinem Aufsatz von 1773 anhand von Shakespeare die Historisierung des Genies vornimmt, um sie am Schluss, im letzten Abschnitt, dann dennoch wieder zu unterlaufen. ${ }^{107}$

Zweitens fällt auf, dass die bisherigen einzelnen Vorschläge zum langfristigen Wissenserhalt und zur Markierung der betreffenden Endlager eine geringe Systematik aufweisen und von Studien nationaler Expertengremien bis hin zu Ergebnissen von Wettbewerben in der Bevölkerung reichen. ${ }^{108}$ Diese fehlende Systematik wurde auch von der RK\&M-Initiative wiederholt explizit festgestellt. ${ }^{109}$ Inzwischen ist also weniger der Mangel an ersten Lösungsansätzen

105 Van Hove 2015, S. 105 f.

106 Vgl. dazu die historische Problematisierung der abendländischen Tradition der Ewigkeitsbehauptungen gegenüber Schriftzeichen in Kapitel 4. dieser Einführung.

107 Vgl. Kapitel IV.3.3.2.

108 Vgl. dazu auch die online zugängliche, kommentierte Reference Bibliography der RK\&MInitiative (https://www.oecd-nea.org/rwm/rkm/). Eine der in der breiten Öffentlichkeit wohl bekanntesten umfassenden Bemühungen, sich mit der langfristigen Markierung von und der Wissensweitergabe zu Lagern für radioaktive Abfälle zu befassen, war der von der US-Regierung in Auftrag gegebene sogenannte „Sandia Report": Trauth/Hora/ Guzowski 1993. Die Zeitschrift für Semiotik hat der Atomsemiotik einst einen ganzen Sonderband gewidmet, ursprünglich erschienen 1984, später neu publiziert unter: Posner 199o.

109 Vgl. etwa Claudel 2015, S. 86 f. Zudem auch Marcos Busers Literaturstudie zum Stand der Markierung von geologischen Tiefenlagern, derer "Gesamteindruck“ lautet: „Verschiedene Länder entwickelten in der Vergangenheit entsprechend ihren individuellen Bedürfnissen Strategien für den Langzeit-Wissenserhalt von Information über Tiefenlager und konkrete Markierungsstrategien an Standorten. Viel Wissen ist inzwischen zusammengetragen worden und verfügbar. Allerdings wird der Eindruck bestärkt, dass eine systematische Ausleuchtung des Themas auf internationaler Ebene erst in den Anfängen steckt. Die Einbindung von Interdisziplinarität wird die Qualität der einzelnen 
das Problem, sondern die Frage, wie man diese wissenschaftlich fundiert beurteilt, auswählt, weiterentwickelt und in ganzheitliche Strategien und Maßnahmen überführt. Die angekündigten abschließenden Dokumente der zweiten Phase der RK\&M-Initiative werden denn auch einen ersten Rahmen für eine verbesserte Systematik schaffen. Die in der vorliegenden Untersuchung erarbeitete Typologie der Operationen zur Ewigkeitsattribuierung von Schriftzeichen hätte dabei das Potenzial, bei entsprechender Adaption künftig entscheidend zu einer solchen Systematik beizutragen.

Drittens liegt im aktuellen Diskurs der Fokus weniger darauf, wie Information möglichst unabhängig von zeitlichen Veränderungen ihrer intelligiblen Seite sowie ihres Kontexts bewahrt, sondern inwiefern diese möglichst langfristig in die jeweiligen Kommunikationszusammenhänge einer Gesellschaft einbezogen werden könnte. Stellvertretend dafür sei Eleni Mitropoulou vom Centre de Recherches Sémiotiques (CeReS) der Universität Limoges zitiert, welche die französische Agence nationale pour la gestion des déchets radioactifs (ANDRA) berät:

We then introduced the premise that it was not marking (consisting in a language, image, symbol or code, etc.) that needed to be made sustainable but rather the process for communicating on it. So the initial hypothesis on the "long-term" communication process (with „long" defined in terms of the Records, Knowledge and Memory project) assumes the need for a „communication system" approach $[\ldots] .^{110}$

With reference to the above conditions, it is important to highlight that one main method of ensuring longevity in terms of integration is not to isolate the repository from people, but rather the opposite. Even if the communication system requires sustainable media it mainly requires sustainable human actions to produce its memory. ${ }^{11}$

Dieser Fokus ließe sich mit der vorliegenden Arbeit auf einer zeichentheoretischen Ebene auch wie folgt zusammenfassen: Momentan - und daran scheint nach dem besten Wissen des Verfassers auch die zweite Phase der RK\&M-Initiative nichts grundlegend geändert zu haben - konzentriert man sich auf diejenigen Strategien, die sich mit der in Kapitel II.1 untersuchten Unteroperation Unendliche Lektüre überschneiden. Man läuft dabei aber Gefahr, nicht nur die dazu komplementäre Unteroperation Unendliches Verstummen zu vernachlässigen, sondern auch die beiden anderen

Ergebnisse in diesem Sinne entscheidend beeinflussen“ (Buser 2010, S. 61). Dieser Eindruck wurde später auch von Eleni Mitropoulou bestätigt (Mitropoulou 2015, S. 94).

110 Mitropoulou 2015, S. 93.

111 Ebd., S. 95. 
Grundoperationen Autonome Performative Produktion und Reflexivität. Aus Sicht der vorliegenden Arbeit ist jenem gegenwärtigen Fokus zwar grundsätzlich zuzustimmen und sind die dabei unternommenen Bestrebungen zu unterstützen. Gerade der Versuch, nach Strategien zu suchen, wie Informationen möglichst autonom gegenüber zeitlichen Veränderungen ihrer intelligiblen Seite und ihres Kontextes bewahrt werden könnten - also ein gleichwertiger Einbezug derjenigen Operationen zur Ewigkeitsattribuierung, die nicht auf Unendlichkeit, sondern auf Autonomie abzielen (vgl. Kapitel 1.1 des Schlussteils) -, sollte dabei aber auf keinen Fall an den Rand gedrängt, sondern im Gegenteil, wo immer möglich, mit den bestehenden Ansätzen kombiniert werden. Dies gilt sowohl in Bezug auf die zu erhaltenden Informationen als auch in Bezug auf die Prozesse des Wissenserhalts selbst. Denn ohne eine solche Kombination droht jener "communication system approach“, der auf "the written form as the best guarantee for reliable transmission",112 auf eine kontinuierliche, unendliche Aktualisation der betreffenden Informationen und damit letztlich einseitig auf die semantische Ebene setzt, dereinst gänzlich und unwiederbringlich in sich zusammenzufallen. Dies wäre dann der Fall, sollte eine künftige Generation den Zugriff auf ebendiese semantische Ebene völlig verlieren, wovon mit Blick auf die Menschheitsgeschichte nahezu mit Sicherheit ausgegangen werden muss. ${ }^{113}$

Beim soeben unter "drittens" Angesprochenen handelt es sich freilich um einen momentanen Fokus, bei dem man sich durchaus offen für den Einbezug weiterer Ansätze zeigt; so lautet ein zentrales Ergebnis der ersten Phase der RK\&M-Initiative:

An important conclusion reached during the course of Phase I of the RK\&M initiative is that there is no single best means of RK\&M preservation over all time scales: a combination of mediated and non-mediated transmission

112 Ebd., S. 94.

113 Hinsichtlich der semantischen Ebene von Schriftzeichen wären das allgemein bekannte Beispiel bislang unentschlüsselte resp. unverständliche Schriften wie etwa im Falle des Etruskischen oder Meroitischen, wo die Lesbarkeit hauptsächlich daran scheitert, dass die betreffende Sprache heute weder genügend bekannt noch vollständig rekonstruierbar ist (vgl. als ersten Überblick Fuls 2009, S. 2 f.; und natürlich die neu bearbeitete Ausgabe der Einführung Ernst Doblhofers: Die Entzifferung alter Schriften und Sprachen, die nicht zufällig „Sprachen“ bereits im Titel führt, ders. 20oo, insbesondere Kapitel VII). Selbst das heutige Verständnis der altägyptischen Sprache und Schriften verdankt sich letztlich bloß einer Verkettung glücklicher Zufälle. Der Zufall musste also selbst einer Kultur zu Hilfe kommen, die (von der Architektur über institutionalisierte Rituale bis hin zur Verwendung der Schrift) eine in der Menschheitsgeschichte bislang einzigartige Gedächtniskultur war (vgl. J. Assmann 1991, insbesondere S. 17) und zudem - im Zeithorizont des nuklearen Zerfalls - lediglich eine geringe Anzahl an Jahrtausenden zurückliegt. 
methods should be preferred (dual-track strategy) within a systemic approach in which the various elements complement and reference to one another. This would provide redundancy and therefore maximise the survivability of a recognisable and comprehensible message. ${ }^{114}$

Eine systematische Kombination aller in der vorliegenden Untersuchung aufgezeigten Operationen mit bislang angedachten, vor allem auf einen mittelfristigen Zeithorizont und die Unteroperation Unendliche Lektüre abzielenden Strategien des Wissenserhalts könnte dereinst vielleicht genau einer solchen „dual-track strategy“ entsprechen.

Im Kontext dieser Überlegungen ist einschränkend darauf hinzuweisen, dass aufgrund der wiederholt angekündigten Publikation des Schlussberichts der zweiten Phase der RK\&M-Initiative zu erwarten ist, dass sich dessen Erscheinen mit den letzten Druck- und Publikationsvorbereitungen der vorliegenden Monographie überschneiden wird, die nicht mehr in den Händen des Verfassers liegen. Das hier zur Initiatve Dargelegte ist also auf seine Aktualität hin zwingend mit dem wohl bald schon einsehbaren Schlussbericht samt dazugehörigen, weiteren noch ausstehenden Dokumenten abzugleichen. ${ }^{115}$

\subsection{Einzelstudien}

Gleich anschließend an die soeben erwähnten Bestrebungen im Bereich des langfristigen Wissenserhalts wären Einzelstudien zu nennen, die sich im Schnittfeld von Archäologie, Linguistik und Literaturwissenschaft bewegen und dabei Fragen zur Ewigkeitsattribuierung von Schriftzeichen zumindest implizit streifen. Als erster Einstieg in dieses Feld wären etwa Stein und Zeit und Das kulturelle Gedächtnis von Jan Assmann, ${ }^{116}$ Aleida Assmanns Im Dickicht der Zeichen und Zeitund Tradition ${ }^{117}$ sowie JesperSvenbros Phrasikleia ${ }^{118}$ zu nennen. Zunächst zum erstgenannten Werk: Viele von Jan Assmanns Überlegungen in Stein und Zeit basieren auf spezifischer Forschung und kulturellen Annahmen zu Leben, Kultur und religiösen Vorstellungen im alten Ägypten, die hier ohne breites Einlesen in die Diskurse der ägyptologischen Forschung der letzten 30 Jahre nicht auf ihre Aktualität hin überprüft werden können. Aus

\footnotetext{
114 Claudel 2015, S. 88.

115 Man halte sich diesbezüglich an die betreffende Website: https://www.oecd-nea.org/ $\mathrm{rwm} / \mathrm{rkm} /$.

116 J. Assmann 1991; ders. 2005.

117 A. Assmann 2015; und dies. 1999.

118 Svenbro 2005 [französische Erstausgabe 1988]. - Für diesen Literaturhinweis danke ich Charles de Roche ebenso wie für seinen Hinweis auf die unten erwähnte Monographie Hans-Jost Freys.
} 
linguistisch-literaturwissenschaftlicher Perspektive aber sind für die vorliegende Arbeit und deren historische Einbettung in die ,Geschichte der Schrift ${ }^{\dagger}$ bemerkenswert:Jan Assmanns These der speziell für Ägypten geltenden Entstehung der Literatur resp. wesentlicher Konstituenten derselben aus der Epigraphik ${ }^{119}$ - mit Anknüpfungspunkten an die Forschungen Uwe Wirths zur Autor- und Herausgeberfiktion um 1800 -;120 seine semiologischen Überlegungen und die Beobachtung einer strukturellen Nähe von Mündlichkeit und epigraphischer Schriftlichkeit ${ }^{121}$ sowie des Zusammenhangs von Verewigungsversuchen mit der vertikalen Hierarchie einer „Kultur des Väterlichen“, ${ }^{122}$ der überraschende Ähnlichkeiten zu David Wellberys Studien zur Genieästhetik des 18. Jahrhunderts aufweist. ${ }^{123}$ Ähnliche Punkte sind für Das kulturelle Gedächtnis zu nennen, das die Studie auf die israelitische und altgriechische Kultur ausdehnt und daraus allgemeine Mechanismen der Wissensweitergabe und der Kanonisierung herausarbeitet - dies aber nicht in Bezug auf innersprachliche Operationen in einzelnen Texten selbst, sondern auf einer allgemeineren Ebene anhand der Unterschiede zwischen mündlicher und schriftlicher Tradierung und außersprachlichen Faktoren wie dem Verhältnis von Herrschaft und Erinnerung, Institutionalisierung, Kodifizierung von Recht, Kanonbildung oder mit Schrift kombiniertem Monumentalbau.

Aleida Assmann setzt sich aus einer Makroperspektive mit kultureller

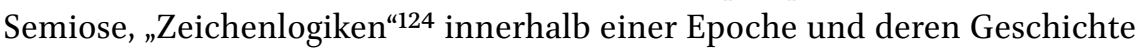
auseinander, was hier insbesondere für die Übertragung des göttlichen Attributs der Ewigkeit auf Schriftzeichen relevant ist, die vor allem im Kapitel zur Genieästhetik aufgegriffen wird. Eine vollständige Integration von Aleida Assmanns Perspektive würde jedoch den Rahmen der vorliegenden Arbeit sprengen. Abgesehen von einzelnen Verweisen - etwa zu Platons (vermeintlichem) Schriftverständnis, zur Geschichte der Hermeneutik, zur Kanonisierung sowie zum Klassischen - kann deshalb nur im Ausblick des Schlussteils darauf zurückgekommen werden.

Jesper Svenbros Studie ist für die hier verfolgten Fragestellungen vor allem dann interessant, wenn er einerseits ausführlich auf die Verknüpfung des Eigennamens mit dem altgriechischen Unsterblichkeitsdiskurs eingeht

\footnotetext{
119 Vgl. J. Assmann 1991, S. 169-199.

120 Vgl. Kapitel II.3.4; und Wirth 2008.

121 Vgl. J. Assmann 1991, S. 76-95 (insbesondere S. 87 f.) und 173.

122 Vgl. ebd., S. 96-137.

123 Vgl. Kapitel IV.3.3; und Wellbery 1996, u. a. S. 127-130.

124 Vgl. A. Assmann 2015, S. 17.
} 
(sowohl in Bezug auf die biologischen als auch die ,schriftlichen' Kinder) ${ }^{125}$ und andererseits die autoreferenzielle sowie autoreflexive, vor allem an die erste Person Singular ${ }^{126}$ geknüpfte Deixis altgriechischer Grab- und Weihinschriften behandelt. Letztere spielt mit dem Verhältnis von Schrift und (Leser-)Stimme, ${ }^{127}$ ein Verfahren, das der Ewigkeitsattribuierung von Schriftzeichen dient und das die vorliegende Arbeit unter den Grundoperationen Unendliche Aktualisation resp. Reflexivität fasst. Zu diesem zweiten hier relevanten Forschungsinteresse Svenbros gehören auch seine Beobachtungen zur altgriechischen Auseinandersetzung damit, dass die Schrift zum Tod der Stimme führe resp. das Verstummen des Schreibers und dessen Tod vorwegnehme ${ }^{128}$ - eine Auseinandersetzung, die etwa schon bei Sappho durch den Zusammenfall des nahen Todes des sprechenden Ichs mit dem Ende des verschriftlichten Gedichtes, in dem dieses Ich spricht, auch ästhetisch eingesetzt wird ${ }^{129}$ und einem Verfahren entspricht, das dann insbesondere in Kapitel II.2 im Zusammenhang mit der Unteroperation des Unendlichen Verstummens und der Fragmentästhetik wiederbegegnet.

Als ein Referenzpunkt aus der neueren Forschung zu Aleida und Jan Assmann sowie Jesper Svenbro wären die Sammelbände Stimme ${ }^{130}$ und Stimme und Schrift ${ }^{131}$ (vor allem dessen umfangreiche Einführung mit zahlreichen Verweisen) zu nennen sowie Bettine Menkes auf Texten von Brentano, Hoffmann, Kleist und Kafka basierende Monographie Prosopopoiia. ${ }^{132}$

Mit Letzterer ist denn auch der Bogen geschlagen von Arbeiten zu antiken Texten hin zu Studien, die sich für die Zeit nach 1800 mit der vorliegenden Arbeit berühren. Als Beispiele hierfür sind etwa die Dissertationen von Stefan Börnchen und Thomas Wortmann zu nennen. Stefan Börnchen entwickelt in seiner Arbeit zu Thomas Manns Doktor Faustus ${ }^{133}$ "[a]usgehend von Paul de Mans Definition der Autobiographie über die rhetorische Figur der

\footnotetext{
125 Vgl. Svenbro 2005, vor allem S. 64-102; und Kapitel III.1.2.2 zu Wallenstein und seiner Tochter Thekla.

126 Vgl. ebd., u. a. S. $136 \mathrm{f}$.

127 Vgl. ebd., vor allem S. 34-46, 81 und 141-143.

128 Vgl. ebd., S. 133-145.

129 Vgl. ebd., S. $138 \mathrm{f}$.

130 Vgl. Kolesch/Krämer 2006.

131 Vgl. Wiethölter/Pott 2008.

132 Menke 200o, insbesondere S. 217-323.

133 Börnchen 2006.
} 
Prosopopöie ${ }^{4134}$ und in expliziter Abgrenzung zu Bettine Menkes Prosopopoiia-Begriff ${ }^{135}$ seine zentrale These,

daß der Doktor Faustus wie sein Intertext Tristram Shandy prosopopoietische oder, genauer, phonopoietische Text-Bestimmungs'-Strategien als Allegorien inszeniert: Tatsächlich, das ist die Hamletlehre des Tristram Shandy, kann nur die Lektüre aus einem ,toten' Buchstabentext, einem Epitaph, einen inspiriert,lebendigen` Text, eine Elegie, machen. Diese hat als Klage jene doppelte Funktion, die Echo in Ovids Metamorphosen verkörpert: Einerseits fingiert das Echo eine ,Stimme-von-jenseits-des-Text-Grabes' und vermag so das Versprechen bio-graphischer Texte zu erfüllen, ,Leben' und ,Stimme' der Toten im Text zu bewahren. Andererseits ist ihre, Stimme', die man im Text zu vernehmen meint, nur das Echo der eigenen Stimme. Daher ist das Echo nicht nur Fiktion der ,Stimme-von-jenseits-des-Text-Grabes', sondern gleichzeitig Klage darüber, daß es sich nur um eine Fiktion handelt. ${ }^{136}$

Die vorliegende Arbeit schließt insofern an ebendiese Beobachtungen zur Prosopopoiia/Prosopopöie und zu deren allegorischen Inszenierung an, als man sagen könnte: Einzelne der untersuchten Operationen zur Ewigkeitsattribuierung zielen gewissermaßen darauf ab, jener in der Prosopopöie fingierten Stimme des Textes Dauer zu verleihen. Thomas Wortmanns Dissertation Literatur als Prozess zum Geistlichen Jahr von Annette von Droste-Hülshoff hingegen ${ }^{137}$ befasst sich wesentlich mit einem ewigen Weiterschreiben - einem Unterfangen, das etwa zeitgleich Helmut Pfotenhauer für Jean Paul beobachtet hat ${ }^{138}$ und das dann insbesondere das historisch-kontextualisierende Kapitel zur Grundoperation Unendliche Aktualisation (II.3) eingehend behandeln wird. Auch zeigt sich in Drostes Geistlichem Jahr besonders exemplarisch die Übertragung der göttlichen Attribute des Schöpferischen und der Ewigkeit auf das schöpferisch-geniale Individuum und dessen Werk. Selbst eine Autorin, die noch an die Botschaft der Heiligen Schrift glaubt, ist in der ersten Hälfte des 19. Jahrhunderts bereits derart von den vorausgegangenen geistes- und literaturgeschichtlichen Entwicklungen geprägt, dass sie an jener Übertragung und damit an der Heiligung

\footnotetext{
134 Ebd., S. 323 .

135 Vgl. ebd., S. 108-110, dazu in nuce: „Während Menke Prosopopoiia und Allegorie als Gegenmodelle begreift, beschreibe ich die Prosopopöie als Allegorie: und zwar als die für die vorliegende Doktor Faustus-Interpretation paradigmatische Allegorie, da sie gleichermaßen eine Schrift-, Stimm- und Musikallegorie ist“ (ebd., S. 108).

136 Ebd., S. 323 .

137 Wortmann 2014.

138 Pfotenhauer 2013.
} 
der Schrift als solcher mitschreibt. ${ }^{139}$ Wortmanns Arbeit ist - zusammen etwa mit dem Sammelband Redigierte Tradition ${ }^{140}$ - außerdem deshalb hier zu nennen, weil sie zum einen für Drostes Schreiben und damit für Texte, die in den Jahrzehnten unmittelbar nach dem hier im Fokus stehenden Zeitbereich entstanden sind, eine Kontinuität von zumindest gewissen, durch die geistesgeschichtlichen Entwicklungen im 18. Jahrhundert geprägten Versuchen der Ewigkeitsattribuierung von Schriftzeichen andeutet. Und zum anderen, weil sie wie schon Bettine Menke, die ebenfalls auf Kafka ${ }^{141}$ und die betreffenden einschlägigen Arbeiten Gerhard Neumanns ${ }^{142}$ verweist, oder Stefan Börnchens Arbeit zu Thomas Mann ${ }^{143}$ diese Kontinuität dahingehend anzudeuten vermag, als dass der akzentuierte Einsatz von Operationen zur Ewigkeitsattribuierung von Schriftzeichen als wesentliche Konstituente der literarischen Moderne gelten könnte. Oder vielleicht treffender formuliert: Bereits bekannte wesentliche Konstituenten der literarischen Moderne könnten vielleicht im akzentuiert auftretenden Versuch der Verewigung mittels Schriftzeichen und der Auseinandersetzung mit derselben historisch begründet werden. Dies ist freilich eine - im Schlussteil noch einmal aufugreifende - Vermutung, die über die vorliegende Arbeit hinaus weiterzuverfolgen wäre.

Hans-Jost Freys Monographie Der unendliche Text ist vielleicht dasjenige Werk der Forschungsliteratur, das der vorliegenden Arbeit in thematischer wie methodischer Hinsicht am nächsten kommt: Die von Frey detailliert untersuchte Möglichkeit, mittels Schriftzeichen intertextuelle Bezüge herzustellen, lässt sich als ein Verfahren beschreiben, das eine potenziell unbeendbare Lektüre ermöglicht und deshalb nach der hier verwendeten Terminologie zur Unteroperation Unendliche Lektüre gezählt werden kann. Frey beweist

139 Vgl. Wortmann 2014, u. a. S. 222, wo er schreibt: „Zum einen handelt es sich um eine radikale Neubestimmung des Genrekonzeptes der Perikopenlyrik: Aus der Frömmigkeitsübung, die das Abfassen der geistlichen Lieder und die Auseinandersetzung mit den Texten der Heiligen Schrift darstellen sollte, wird ein Schreibzyklus, in dem es weniger um eine Beschäftigung mit den Perikopen geht, sondern vielmehr um das Schreiben selbst, für die [sic] Kirchenjahr und die Heilige Schrift nur noch als kompositorische Fixpunkte fungieren, die das Schreiben leiten und rahmen. Die Zweckdichtung, als die die Perikopenlyrik verstanden wurde, wird zweckentfremdet; dem heteronomen Literaturkonzept wird ein radikal autonomes gegenübergestellt, nämlich ein Schreiben, das sich selbst zum Zweck und Ziel wird." Zum Stichwort ,autonom 'vgl. insbesondere das Kapitel IV.3.2 zur Autonomieästhetik.

140 Liebrand/Hnilica/Wortmann 2010.

141 Vgl. Wortmann 2014, insbesondere S. 221-226.

142 Vgl. u. a. Neumann 1982, S. 92-112; und ders. 2010, S. 339-364.

143 Vgl. bezüglich Thomas Mann auch Nilges 2018. 
anhand ausgewählter literarischer Beispiele die Einseitigkeit von Genettes Modell, worin sich lediglich der spätere Text auf den früheren beziehen kann:

Ihr [der einseitigen Beziehung des Hypertextes auf den Hypotext, MG] steht die reziproke Textbeziehung gegenüber, bei welcher nicht nur der spätere Text vom früheren her, sondern auch der frühere vom späteren her gelesen wird. In der reziproken Textbeziehung ist weder die Chronologie der Texte noch deren Bedeutung verneint, sondern das voreilige Dogma von der Unveränderlichkeit der Texte. [...] Die Texte dauern in der Veränderung. Deshalb können sie nicht auf ihren Ort in der Abfolge festgelegt werden, sondern sind immer dann gegenwärtig, wenn etwas mit ihnen geschieht, und was mit ihnen geschieht, verändert sie. ${ }^{144}$

Der Verfasser würde dem zustimmen, wenn der Begriff „dauern“ sich hier als potenzielle Bewegung verstehen lässt, die sehr flüchtig ist. Eine ausführlichere Auseinandersetzung mit Frey wird im Kapitel II.2.2 zu Hölderlins Ode Ermunterung erfolgen.

Was die von Frey festgestellte Unverortbarkeit der Texte in einer chronologischen Abfolge anbelangt, so führt dies zu Daniel Müller Nielabas Aufsatz Vom Bedeuten des Literarischen: Verstehen, verschoben, ${ }^{145}$ der nicht nur die Unverortbarkeit von Text, sondern - weitaus umfassender - auch vom Verstandenen nahelegt. ${ }^{146}$ Mit dem potenziell sich endlos verschiebenden Verstehen, das der Ausblick des Schlussteils später noch einmal aufgreift, und der damit verbundenen, potenziell ewigen Lektüre von Schriftzeichen gelangt man wieder zur Auseinandersetzung mit der hermeneutischen Tradition, womit sich der Kreis dieser Skizze zum allgemeinen Forschungsstand schließt.

\subsection{Fazit}

Es hat sich gezeigt, dass die Forschung zu Schrift und Literatur im Zusammenhang mit Ewigkeit und Verewigung bereits in der Auseinandersetzung mit der altägyptischen wie altgriechischen Schriftkultur indirekt in die Nähe von Operationen zur Ewigkeitsattribuierung von Schriftzeichen gelangt ist, während sie diese auch in Studien zu Texten für die Zeit um 1800 (siehe dazu vor allem auch die historischen Kapitel des Hauptteils) und darüber hinaus immer wieder streift. Eine systematische Untersuchung solcher Operationen - sei es anhand von schriftlichen Zeugnissen um 1800 oder aus einer anderen Zeit - fehlt hingegen nach bestem Wissen des Verfassers erstaunlicherweise bis heute. Ein möglicher Grund dafür liegt sicherlich in der

\footnotetext{
144 Frey 1990, S. 20.

145 Müller Nielaba 2005, S. 37-52.

146 Vgl. ebd., S. 40.
} 
heutigen institutionellen Trennung der Philologien in die Teilbereiche Linguistik und Literaturwissenschaft, was einerseits den Blick schärfen, andererseits aber manchmal auch arbiträre, den Gegenständen nicht immer angemessene Grenzziehungen und einseitige Perspektiven nach sich ziehen kann. ${ }^{147}$ Ein wohl noch wesentlicherer Grund hat - wie am Ende der knappen Auseinandersetzung mit der hermeneutischen Tradition angedeutet - paradoxalerweise mit der Ewigkeitsbehauptung und -attribuierung von Schriftzeichen selbst und der Entstehung der modernen Philologien im 18. und 19. Jahrhundert zu tun, worauf das letzte Kapitel der vorliegenden Arbeit noch einmal zurückkommen wird.

\section{Historische Problematisierung der, abendländischen Ewigkeitsbehauptungen gegenüber Schriftzeichen - eine Skizze}

Weiter oben wurden die Begriffe Ewigkeitsbehauptung gegenüber Schriftzeichen und Ewigkeitsattribuierung von Schriftzeichen als eine für die vorliegende Arbeit zentrale Unterscheidung eingeführt. Ebenso wurde klargestellt, dass der Fokus der Untersuchung nicht auf den Ewigkeitsbehauptungen, sondern auf den Operationen zur Ewigkeitsattribuierung und deren historischer Kontextualisierung in der Zeit um 1800 liegt. Dennoch ist es für das Verständnis und die Rahmung des Hauptteils sinnvoll, hier vorangestellt aus historischer Perspektive noch etwas ausführlicher auf die Ewigkeitsbehauptungen gegenüber Schriftzeichen einzugehen. Dabei geht es dezidiert nicht darum, eine umfassende Geschichte dieser Ewigkeitsbehauptungen zu schreiben oder etwa eine seitenlange Liste mit expliziten Textstellen dazu aufzuführen.

Werke, die sich ansatzweise mit einer solchen Geschichte der Ewigkeitsbehauptungen berühren, wären etwa die betreffenden Arbeiten von Martina Stercken und Christian Kiening, ${ }^{148}$ aber vor allem die oben bereits erwähnten Forschungen Aleida und Jan Assmanns, Jesper Svenbros sowie die dereinst drei Bände umfassende Reihe Konzeptionen des Unendlichen - eine europäische Kulturkonstante?. Zudem ist hier auch Philipp Theisohns Monographie Die kommende Dichtung hervorzuheben. ${ }^{149}$ Zur Geschichte der Schrift vergleiche

147 Vgl. dazu u. a. Bleumer et al. 2013. Zu grundsätzlichen Überlegungen zu „Reziproke[n] Nutzbarkeiten“ von Linguistik und Literaturwissenschaft vgl. Linke/Müller Nielaba 2013.

148 Vgl. Kiening/Stercken 2008; und (stellenweise identisch) Kiening 2016.

149 Theisohn 2012. Ein ausführliches In-Bezug-Setzen der vorliegenden Monographie mit derjenigen Theisohns würde in eine weitere Monographie münden; stellvertretend und als ein möglicher Ausgangspunkt für ein solches Unterfangen kann hier deshalb nur 
man etwa Harald Haarmanns Standardwerk Universalgeschichte der Schrift 150 (inklusive der darauf basierenden Texte desselben) und den vierbändigen Katalog der Grazer Ausstellung Der Turmbau zu Babel, Ursprung und Vielfalt von Sprache und Schrift, ${ }^{151}$ der aufgrund seiner zahlreichen Beiträge namhafter Wissenschaftler sowie Abbildungen und Tabellen einen hervorragenden ersten Überblick über die globale Sprach- und Schriftgeschichte der Menschheit verschafft. Betreffend die Geschichte der Diskurse zum Verhältnis von Stimme und Schrift vergleiche man ebenfalls die im vorangegangenen Kapitel genannten Titel. Zur Geschichte der abendländischen Tradition der Hermeneutik, die wesentlich an der Ewigkeitsbehauptung gegenüber Schriftzeichen beteiligt ist, vergleiche man als ersten Überblick den Band von Meinrad Böhl et al., ${ }^{152}$ des Weiteren u. a. die Forschungen Emil Angehrns ${ }^{153}$ oder, älteren Datums, Peter Szondis Einführung in die literarische Hermeneutik. ${ }^{154}$

In diesem Unterkapitel hingegen geht es um eine skizzenhaft vorgetragene, grundsätzliche Problematisierung der Tradition der Ewigkeitsbehauptungen gegenüber Schriftzeichen, die zumindest im abendländischen Kulturraum eine jahrtausendealte Geschichte aufweist, bis heute anhält und gerade in der gegenwärtig sich vollziehenden digitalen Medienrevolution vielleicht so präsent und wirkmächtig ist wie nie. ${ }^{155}$ Dieses geschichtliche Erbe gilt es - insbesondere auch in seiner Problematik angesichts der semiotischen Flüchtigkeit von Schriftzeichen - für den Hauptteil im Hintergrund stets mitzubedenken und in den historisch-kontextualisierenden Kapiteln spezifisch für die Zeit um 1800 wieder aufzugreifen.

folgende Stelle aus Die kommende Dichtung zitiert werden: „Das Bündnis, das Mantik und Dichtung im 15. Jahrhundert eingegangen waren, hatte seinen Zweck in der Ausarbeitung einer Redeform gehabt, welche die Menschheit zu einem Gesprächspartner der Vorsehung - in welcher Form auch immer sie gedacht wurde - erheben sollte. Es handelte sich dabei [...] um kein uneigennütziges Bündnis. Die Dichtung hatte sich nicht zuletzt dort hinein gefügt, weil es ihr dabei auch um die Selbstsicherung, das Vorsehen der eigenen Zukunft ging. Das Medium der Vorsehung ist immer auch selbst Teil der Vorsehung, es hat seinen Platz in dieser Welt garantiert" (ebd., S. 470).

150 Vgl. Haarmann 1991.

151 Seipel 2003, Band IIIA: Schrift.

$15^{2}$ Böhl/Reinhard/Walter 2013.

153 Vgl. Angehrn 2004; und ders. 2008.

154 Szondi 1975, S. 7-191.

155 Vgl. dazu etwa Krüger 2004, insbesondere S. 401-413. 


\subsection{Schrift als dominantes Medium im Diskurs der Verewigung: Buchreligionen und Schriftzentrismus}

Die expliziten und impliziten Ewigkeitsbehauptungen erhalten im abendländischen Kulturraum durch die Anerkennung des Christentums im Römischen Reich und dessen Erhebung zur Staatsreligion - eines mindestens 250 Jahre dauernden, schrittweisen Prozesses von den Toleranzerklärungen der Kaiser Galerius (311) und Konstantin I. (313) über die Regierungszeit Theodosius' (379-394) bis zu den Schließungen der letzten heidnischen Tempel unter der Herrschaft Justinians $(527-565)^{156}$ - einen mächtigen Fürsprecher: Die Buchreligionen des Judentums und des Christentums zelebrieren ${ }^{157}$ sowohl explizit als auch implizit die Behauptung, Schrift könne Dinge für die Ewigkeit - resp. zumindest bis zum Jüngsten Tag - festhalten. Die für den Inhalt behauptete ewige Gültigkeit der heiligen Schriften erstreckt sich dabei unmerklich auch metonymisch auf das Medium selbst, die Schrift. Zum Teil wird diese Übertragung auch bewusst forciert, etwa wenn christliche Autoren „an den vielfältigen Entsprechungen zwischen den beiden großen Büchern, dem liber naturae und dem liber scripturae", arbeiten, indem sie „zentrale Momente der Heilsgeschichte in Metaphern der Buchschriftlichkeit“ ${ }^{158}$ fassen, was bereits dem Versuch einer Ewigkeitsattribuierung von Schriftzeichen entspricht, bei der sowohl die Grundoperation Reflexivität als auch die Grundoperation Autonome Performative Produktion zum Einsatz kommen. ${ }^{159}$ Diese Übertragung schließt dabei an andere explizite wie implizite Ewigkeitsbehauptungen gegenüber Schriftzeichen an, wie sie etwa in Weih-, Grab- und Siegesinschriften schon lange vor der Niederschrift des Alten und erst recht des Neuen Testaments in Europa und im Nahen Osten präsent waren; ${ }^{160}$ und sie geht vor allem einher mit einem sich im Mittelmeerraum und im Nahen Osten vom ca. 14. vorchristlichen bis zum 7. nachchristlichen Jahrhundert sukzessive vollziehenden Übergang von einer hauptsächlich mündlich-rituellen hin zu einer vor allem schriftlich-institutionellen Organisationsform des kulturellen Gedächtnisses. ${ }^{161}$

156 Lexikon für Theologie und Kirche, Bd. 7, Sp. 303 f., und Bd. 5, Sp. 1108 f.

157 „Zelebrieren“ kann dabei durchaus auch wortwörtlich verstanden werden, z. B. in der katholischen Liturgie.

158 Kiening 2016, S. 179 .

159 Eine Analyse solcher christlichen Textstellen vor dem Hintergrund der in der vorliegenden Monographie erarbeiteten Typologie wäre demnach äußerst vielversprechend.

16 o Vgl. Haarmann 2011, u. a. S. 20-22.

161 Vgl. J. Assmann 2005, u. a. S. 289-292. Zum wohl prägenden orientalischen Einfluss, gerade was die Heiligkeit von Schriften anbelangt, vgl. zudem ebd., S. 277. 
Berühmtestes Beispiel für eine starke (implizite) Ewigkeitsbehauptung einer heiligen Schrift von Juden- und Christentum gegenüber dem Medium der Schrift im Allgemeinen ist der Empfang der Gesetzestafeln, wie ihn das Zweite Buch Mose berichtet. ${ }^{162}$ Freilich wird in dieser Erzählung - so zeigen Moses Zerschlagen der von Gott beschriebenen Tafeln im Zorn und die anschließende Neuschreibung (dieses Mal aber durch Moses) ${ }^{163}$ - gerade am Beispiel der Gesetzestafeln zugleich auch die Vergänglichkeit der Materialität der Schrift resp. der Schriftträger auf komplexe Weise mitbehandelt. ${ }^{164}$

Auch die über Jahrhunderte hinweg mit dem Juden- und Christentum konkurrierende, dritte monotheistische Religion, der Islam, stützte und stützt sich auf eine heilige Schrift. Das „Verbot, lebende Wesen direkt abzubilden“, das im arabisch-islamischen Raum insbesondere bezüglich Allah und seines Propheten vorherrschend war und ist, führte zu einer eigenen sakralen Kalligraphie, ${ }^{165}$ die noch sichtbarer und gestalterisch-architektonisch präsenter eingesetzt wurde als die Schrift im Juden- und Christentum (man denke etwa an die Verzierungen in der berühmten Burganlage Alhambra von Granada). Auch im Falle der islamischen Kalligraphie besteht eine Verbindung zu weitaus älteren Traditionen, was kalligraphische Inschriften in Südarabien belegen, die bis ins 8. Jahrhundert vor Christus zurückreichen. ${ }^{166}$

Die zwischen diesen drei monotheistischen Religionen vor sich gehende Auseinandersetzung um den Wahrheitsanspruch des jeweiligen heiligen Buches mindert den Anspruch dieser Texte und damit auch deren explizite wie implizite Ewigkeitsbehauptungen (vorerst) nicht. Da alle drei Religionen sich auf (einander noch überschneidende) ,ewig gültige' Schriftkorpora berufen, können die gegenseitigen Angriffe nur auf den Inhalt und die göttliche

162 Vgl. Exodus 24,4+7+12; 31,18; 32,15-16. Diese implizite Ewigkeitsbehauptung, die das Buch Mose an dieser Stelle vornimmt, wird dabei (vor dem Hintergrund der vorliegenden Arbeit wenig überraschend) bereits unterstützt durch mindestens eine Grundoperation zur Ewigkeitsattribuierung von Schriftzeichen, nämlich den Verweis eines Textes auf sich selbst und die eigenen Möglichkeitsbedingungen, und zwar indem der Text der Gesetzestafeln den im Buch Mose wiedergegebenen Gesetzen entspricht; ein Selbstverweis, der dann etwa bei den letzten Anordnungen des Mose (Deuteronomium 31,9-13) im Buch Josua (vgl. Josua 8,31-35) oder im zweiten Buch der Könige (vgl. 2. Könige 22,8-17) wiederholt wird (vgl. Kiening/Stercken 2008, S. 23). In literaturgeschichtlicher Hinsicht haben wir es hier geradezu mit dem Prototypus für das Buch im Buch für die spätere christlichabendländische Literatur zu tun, einer autoreflexiven Operation, der im Kapitel IV.1.1 zu Novalis' Heinrich von Ofterdingen wiederbegegnet wird.

163 Vgl. Exodus 32, 19; 34, 1+4+27-29.

164 Vgl. Kiening/Stercken 2008, S. 22 f.; und Weigel 2006, S. $20-22$.

165 Vgl. Haarmann 2011, S. 71.

166 Vgl. ebd., S. 74. 
Inspiration der Autoren, nicht aber auf das Medium an sich zielen, denn andernfalls entzöge man der eigenen Argumentation die Grundlage. Es ist deshalb - selbst wenn nicht oder nur mit enormem Aufwand wissenschaftlich messbar - anzunehmen, dass die Vorstellung, Schrift könne durch sie vermittelte Inhalte verewigen, durch die Konkurrenz der drei Buchreligionen nicht geschwächt, sondern vielmehr durch diesen gemeinsamen Nenner noch verstärkt wurde.

Hingegen bricht der schon dem Buch Mose inhärente und im Falle des Empfangs der Gesetzestafeln ausgestellte Widerspruch zwischen behaupteter Ewigkeit der Heiligen Schrift und des Wortes Gottes einerseits und der semiotischen Flüchtigkeit und materiellen Vergänglichkeit von Schrift und Schriftträgern andererseits ${ }^{167}$ über die Jahrhunderte hinweg immer wieder auf und beschäftigt Theologen von Augustinus bis Friedrich Schleiermacher. ${ }^{168}$ Ein pointiertes literarisches Beispiel aus der deutschsprachigen christlichen Literatur für ein solches Aufbrechen wäre etwa eine Stelle aus Andreas Gryphius' Catharina von Georgien, wo ausgerechnet im Kontext einer Buchreligion gegen die Verewigung durch Schrift religiös argumentiert wird:

Ihr die jhr glaubt daß euer Feder Macht Den Tod vnd Zeit hab' an ein Joch gebracht? Glaubt frey die Ewigkeit beruht nicht auff Papir. ${ }^{169}$

Dieser Widerspruch führt jedoch bemerkenswerterweise nicht dazu, dass die Betonung der semiotischen und materiellen Flüchtigkeit und Vergänglichkeit des Mediums der Schrift im abendländischen Kulturraum nachhaltig und in einem dominanten Diskurs die Ewigkeitsbehauptung gegenüber Schriftzeichen grundsätzlich verdrängt hätte. Selbst ,die Aufklärung` - und dies wird im Rahmen der historischen Kontextualisierungen, die die vorliegende Arbeit vornehmen wird, entscheidend sein - übt letztlich keine konsequente Kritik an den Ewigkeitsbehauptungen bezüglich des Mediums der heiligen Schriften, sondern an den Ewigkeitsversprechen und -ansprüchen, die in diesen Schriften auf inhaltlicher Ebene formuliert werden. ${ }^{170}$

167 Vgl. Kiening/Stercken 2008, S. 22-26. Dort auch zur Parallele zwischen der unten zitierten Textstelle im Phaidros resp. der ,Seelenschrift' von Sokrates und dem Zweiten Korintherbrief, wo „Paulus, auf der Linie Platons, die folgenreiche Opposition zwischen einer toten und einer lebendigen Schrift" begründe (ebd., S. 24).

168 Vgl. etwa Kiening 2016, insbesondere S. 129-131 und $178 \mathrm{f}$.

169 Gryphius, Catharina von Georgien, S. 14 f.

17 Vgl. u. a. Böhl 2013, S. 217-224. 
$\mathrm{Zu}$ den Buchreligionen tritt hinzu, dass bereits Jahrhunderte vor der Entstehung und Ausbreitung des Christentums in dem für die Ausbreitung der abendländischen Schriftlichkeit zentralen griechischen Kulturraum ebenso die Ewigkeitsbehauptung gegenüber und nicht die Betonung der Flüchtigkeit von Schriftzeichen den entsprechenden Diskurs bestimmte. Das bemerkenswerteste Beispiel dafür findet sich wohl in der berühmten Textstelle in Platons Phaidros, ${ }^{171}$ wo die Figur Sokrates die ägyptische Erzählung des ägyptischen Königs Thamus und des Gottes Theuth (Thot, in der ägyptischen Mythologie u. a. der Erfinder der Schrift) vorträgt und damit seine Argumentation für die Minderwertigkeit der Schrift gegenüber der (dialektischen) Rede einleitet:

\begin{abstract}
Als er aber zu den Buchstaben kam, sagte Theuth: „Diese Kunde, o König, wird die Ägypter weiser machen und ihr Gedächtnis erhöhen, denn zur Arznei für Gedächtnis und Weisheit wurde sie erfunden.“ Der aber erwiderte: „O kunstreicher Theuth, ein anderer ist fähig, die Werkzeuge der Kunst zu erzeugen, ein andrer wieder zu beurteilen, welches Los von Schaden und Nutzen sie denen erteilen, die sie gebrauchen werden. Auch du sagtest jetzt als Vater der Buchstaben aus Zuneigung das Gegenteil dessen, was sie bewirken. Denn wer dies lernt, dem pflanzt es durch Vernachlässigung des Gedächtnisses Vergeßlichkeit in die Seele, weil er im Vertrauen auf die Schrift von außen her durch fremde Zeichen, nicht von innen her aus sich selbst die Erinnerung schöpft. Nicht also für das Gedächtnis, sondern für das Erinnern erfandest du ein Mittel. Von der Weisheit aber verleihst du deinen Schülern den Schein, nicht die Wahrheit. Denn wenn sie vieles von dir ohne Unterricht gehört haben, so dünken sie sich auch Vielwisser zu sein, da sie doch größtenteils Nichtwisser sind, und sie sind lästig im Umgang, da sie statt Weise Dünkelweise geworden sind.["] ${ }^{172}$

$[\ldots]$

6o. SoKRATEs. Wer also glaubt, seine Kunst in Buchstaben zu hinterlassen, und wer sie wieder aufnimmt, als ob etwas Klares und Festes aus Buchstaben zu gewinnen sei, der strotzte von Einfalt und kennte in Wirklichkeit nicht den Wahrspruch Ammons, da er sich einbildete, die geschriebenen Reden bedeuteten noch irgend etwas [sic] mehr, als den schon Wissenden an das zu erinnern, wovon das Geschriebene handelt. ${ }^{173}$
\end{abstract}

171 Vgl. A. Assmann 2015, S. 310 f.; Kiening 2008, S. 21; aber insbesondere Svenbro 2005, S. 33, 161-194, vor allem ab S. 178.

172 Die Rede des Königs ist hier zu Ende, in der verwendeten Edition fehlt jedoch ausgerechnet das Schlusszeichen (die altgriechische Vorlage kam gänzlich ohne Anführungs- und Schlusszeichen aus), weswegen es hier ergänzt wurde. ,Ausgerechnet', da das doppelte Anführungs- und Schlusszeichen dasjenige Schriftzeichen ist, das wie kein anderes darauf verweist, was es selbst nicht ist: auf direkte Rede; vgl. Müller Nielaba 2009.

173 Platon, Phaidros, Kapitel 59 f. resp. S. 86 f. 
Die Schrift erwecke nur den Schein, selber sprechen zu können, sie vermöge auch nicht auf Fragen zu antworten, zeige immer nur dasselbe und wisse weder, zu wem sie reden solle und zu wem nicht. ${ }^{174}$ Deshalb „bedarf sie immer der Hilfe des Vaters, denn selbst vermag sie sich weder zu wehren noch zu helfen“. ${ }^{175}$ Die biologische Fortpflanzungsmetaphorik von Vater ${ }^{176}$ resp. Eltern und Kind, die schon zu Beginn der Einführung aus Platons Symposion zitiert wurde und die dort die Figur Diotima auf die schriftlichen Werke anwendet, kommt hier also wieder zum Zug und wird sodann von der Figur Sokrates auch auf das Medium der Rede übertragen:

\begin{abstract}
Aber viel schöner, glaube ich, ist der Eifer um die gleichen Dinge, wenn jemand, dialektische Kunst anwendend, die geeignete Seele wählt und sie bepflanzt und besät mit Reden der Erkenntnis, die sich selber und dem Sämann zu helfen geschickt und nicht früchtelos sind, sondern Samen tragen, aus dem sie immer von neuem in andern Seelen keimend ihn für ewig unsterblich zu machen geeignet sind und seinen Träger so glücklich zu machen, als es einem Menschen nur möglich ist. ${ }^{177}$
\end{abstract}

Die in diesen Passagen des Phaidros entworfene, vermeintliche Entlarvung der Ewigkeitsbehauptung gegenüber Schriftzeichen als eine semiologisch ungerechtfertigte und die gleichzeitig etablierte Ewigkeitsbehauptung gegenüber der mündlichen (dialektischen) Rede weisen jedoch einen entscheidenden performativen Selbstwiderspruch auf: Sokrates' Argumentation vollzieht sich zwar in einer (dialektischen) Rede, aber diese ist eine verschriftlichte Rede in einem schriftlichen Werk Platons, wobei Phaidros und Sokrates nicht als sprechende Personen aus Fleisch und Blut auftreten, sondern als Figuren eines Textes. Dieses Unterlaufen des Inhalts des Phaidros durch das Medium und die Form desselben ist denn auch in nuce lesbar, wenn an entscheidender Stelle ausgerechnet eine Schriftmetaphorik herbeigezogen wird:

SOKRATES. Und weiter! Wollen wir nicht eine andere Rede [als die schriftliche, MG] betrachten, den echtgeborenen Bruder von dieser, in welcher Art sie entsteht und um wieviel sie durch ihr Wesen besser und mächtiger ist als diese?

Phaidros. Welche meinst du, und wie soll sie entstehen?

\footnotetext{
174 Ebd., Kapitel 59 f. resp. S. 87 f. Vgl. dazu auch Svenbro 2005, S. 33 (insbesondere Anm. 12) und dann vor allem S. $161 \mathrm{f}$.

175 Platon, Phaidros, Kapitel 6o resp. S. 88.

${ }_{176}$ Zum Väterlichen vgl. auch David Wellberys Beobachtungen im Zusammenhang mit der Genieästhetik des 18. Jahrhunderts, die im Kapitel IV.3.3 aufgegriffen werden.

177 Platon, Phaidros, Kapitel 61 resp. S. 89 f.
} 
SoKRATES.Jene, die mit Erkenntnis geschrieben wird in die Seele des Lernenden, die fähig ist, sich selbst zu verteidigen, die zu reden und zu schweigen weiß, gegen wen sie beides soll.

Phaidros. Du meinst die lebende und beseelte Rede des Wissenden, deren Abbild man mit Recht die geschriebene nennen kann.

61. Sokrates. Die meine ich. [...]. ${ }^{178}$

Damit macht ausgerechnet die Figur Sokrates (und mit ihm Platon), die sich gerade im Phaidros kritisch gegenüber der Rhetorik äußert, den ,Fehler', dass die von ihr hier rhetorisch eingesetzte Figur der inhaltlichen Analogie über die Schriftmetaphorik ${ }^{179}$ eine widerspruchsvolle Eigendynamik entfaltet. Die vermeintliche Unsterblichkeit der oben zitierten Rede gründet ebenso wie die ihrer ,Väter' (sei es Platon oder Sokrates oder beide) also ausgerechnet darin, dass diese Rede verschriftlicht wurde. Ohne Platons Niederschrift wäre die Argumentation der Person Sokrates - vorausgesetzt, er hat sie überhaupt je vorgetragen - vielleicht schon zum Zeitpunkt der Niederschrift des Phaidros weitgehend in Vergessenheit geraten. Auch dass Platon die Ansichten Sokrates' in Form von Dialogen verschriftlicht, ist eine Operation, die in diesem Fall nicht für das Medium der gesprochenen Rede, sondern für die Schrift sinnvoll ist: Könnten wir heute noch immer Zeugen davon sein, wie die Person Sokrates tatsächlich zur Person Phaidros spricht, würden diese nicht in einer durchgehenden ${ }^{180}$ Binnenerzählung miteinander sprechen, in der sie selbst als die beiden Figuren aufträten. Nun ist es aber so, dass Platon, der über Sokrates für die mündliche (dialektische) Rede Ewigkeit behauptet, dies in der Form einer verschriftlichten Rede tut, was dem performativen Versuch gleichkommt, nicht nur schriftlich auf eine Rede zu verweisen, sondern diese im Zuge der Lektüre auch vollziehen zu lassen - und damit Sokrates' Rede wieder zum Leben zu erwecken, was zugleich auch der Beweis für deren Unsterblichkeit wäre. Oder mit anderen Worten: Platon bedient sich hier einer innersprachlichen Operation ${ }^{181}$ der Ewigkeitsattribuierung von Schriftzeichen, im Versuch, die Ewigkeitsbehauptung gegenüber der mündlichen Rede zu bewahrheiten, was jedoch letztlich bloß die Ewigkeitsbehauptung gegenüber Schriftzeichen stärkt.

Platons Text Phaidros markiert also - entgegen dem Inhalt der darin enthaltenen Rede von Sokrates - geradezu den Beginn des Siegeszuges der

178 Ebd., S. 88.

179 Zur (Metaphorik der) Seelenschrift vgl. Svenbro 2005, S. 163 f.; aber auch den Zweiten Korintherbrief; resp. Kiening/Stercken 2008, S. 22-26.

180 Punktuell kann aber durchaus eine gleichnishafte Binnenerzählung vorkommen, wie diejenige von Theut und dem ägyptischen König.

181 Vgl. Kapitel III.1 zur Unteroperation Poetische Performativität. 
Ewigkeitsbehauptung gegenüber Schriftzeichen im abendländischen Diskurs: Die Meinung von Sokrates, der selbst keine schriftlichen Zeugnisse hinterlassen hat, ist höchstens noch eine, die schriftlich zitiert einer Figur Sokrates in den Mund gelegt wird. Und zwar von seinem Schüler Platon, der - ob bewusst oder unbewusst - offenbar nicht mehr darauf vertraut, dass sowohl Sokrates' Reden als auch die eigenen ohne (mit Operationen zur Ewigkeitsattribuierung versehene) Verschriftlichung überdauern werden. (Auf die mit der Gründung der Akademie verbundenen, der Kanonisierung der heiligen Texte der Buchreligionen ähnelnden Vorkehrungen Platons, ${ }^{182}$ die ermöglichen sollten, dass seine Schriften sich auch nach seinem Tod verteidigen und Fragen beantworten können, hat Jesper Svenbro hingewiesen. $)^{183}$

Damit verweist die soeben dargelegte Lektüre des Phaidros zwar auf denselben performativen Widerspruch bei Platon, den bereits Jacques Derrida in La Dissémination (1972) im Zuge seiner ausführlichen Auseinandersetzung mit Platons und Sokrates' Positionen zum Verhältnis Mündlichkeit und Schriftlichkeit im Allgemeinen ${ }^{184}$ und der oben zitierten Stelle im Phaidros im Speziellen beobachtet hat. Aber sie zieht daraus einen anderen Schluss als Derrida, der zur Metaphorik der ,Seelenschrift' der oben zitierten Textstelle im Phaidros schreibt:

Inhaltlich hat diese Replik [des Sokrates, MG] nichts Originelles, Alkidamas sagte fast dasselbe. Sie markiert jedoch eine Art Umkehrung im Gang der Argumentation. [...] Einem Schema gemäß, das die gesamte ,abendländische‘ Philosophie beherrschen wird, wird eine gute (natürliche, lebendige, wissende, intelligible, innerliche, sprechende) Schrift einer schlechten (künstlichen, todgeweihten, unwissenden, sinnlichen, äußerlichen, stummen) Schrift gegenübergestellt. Und die gute kann nur in der Metapher der schlechten bezeichnet werden. Die Metaphorizität ist die Logik der Kontamination und die Kontamination der Logik. Die schlechte Schrift ist für die gute gleichsam ein Vorbild sprachlicher Bezeichnung und ein Trugbild eines Wesens. Und wenn das Netzwerk der Gegensätze von Prädikaten, welche eine Schrift auf die andere beziehen, in seinem Gefüge alle begrifflichen Gegensätze des „Platonismus" enthält - hier als die dominante Struktur der Geschichte der Metaphysik betrachtet -, so wird man sagen können, daß die Philosophie sich im Spiel zweier Schriften abgespielt habe. Wo sie doch allein zwischen Sprechen und Schrift hat unterscheiden wollen.

Es bestätigt sich im weiteren, daß die Schlußfolgerung des Phaidros weniger eine Verdammung der Schrift im Namen des gegenwärtigen Sprechens ist, denn

182 Dies wären dann außersprachliche Versuche der Ewigkeitsattribuierung, die nicht Gegenstand der vorliegenden Arbeit sind.

183 Vgl. Svenbro 2005, S. 190-194.

184 Vgl. Derrida 1995, vor allem S. 73-19o; als Überblick vgl. Krämer 20o1, insbesondere S. $222-225$. 
die Bevorzugung einer Schrift gegenüber einer anderen, einer fruchtbaren Spur gegenüber einer sterilen Spur, eines zeugungsfähigen, weil im Drinnen abgelegten Samens gegenüber einem im Draußen in reinem Verlust: im Risiko der Dissemination, vergeudeten Samen. ${ }^{185}$

Selbst Derridas eigene Metaphorik - im Paradigma der Fruchtbarkeit, des Samens und des Ausstreuens desselben angesiedelt - lässt sich nämlich vor dem Hintergrund des oben Dargelegten in einen anderen Bezug zum performativen Widerspruch im Phaidros setzen: Mit Blick auf die Ewigkeitsbehauptung gegenüber Schriftzeichen schwingt in Platons schriftlich festgehaltener Schriftmetaphorik implizit durchaus selbst eine Metaphorik der Fruchtbarkeit und des Samens mit: Platons eigene, zu Beginn dieser Einführung zitierte Metaphorik des Zeugens schriftlicher Nachkommen, die er im Symposion Diotima in den Mund legt. Eine Metaphorik, die die Schrift eben gerade nicht für unfruchtbar hält.

Jacques Derrida mag also zwar in Bezug auf den Diskurs zum grundsätzlichen Verhältnis von mündlichen und schriftlichen Äußerungen von einer (freilich inzwischen in vielen Teilen von der Forschung relativierten oder zurückgewiesenen) abendländischen Tradition des Logo- resp. Phonozentrismus, einer Vorherrschaft der Mündlichkeit, schreiben. ${ }^{186}$ Im Falle der Frage aber, welches Medium die transportierten Inhalte am dauerhaftesten festzuhalten vermöge, kann von einem Logozentrismus nicht die Rede sein. Vielmehr deutet alles darauf hin, dass zumindest für diese Frage von einem ,abendländischen Schriftzentrismus‘ gesprochen und geschrieben werden müsste.

Der Widerspruch zwischen behaupteter Ewigkeit von Schriftzeichen im Allgemeinen sowie heiligen Schriften im Speziellen einerseits und der semiotischen Flüchtigkeit und materiellen Vergänglichkeit von Schrift andererseits bricht also zwar immer wieder auf, hat jedoch nie dazu geführt, dass innerhalb des abendländischen Diskurses über die Schrift die Ewigkeitsbehauptung gegenüber Schriftzeichen ihre Dominanz über die Zweifel an ebendieser Behauptung verloren hätte - und dies über einen Zeitraum hinweg, der von mindestens Platons Phaidros bis in die aktuelle Gegenwart des 21. Jahrhunderts reicht. Selbst der Anfang des Johannesevangeliums, der beim Begriff Logozentrismus sofort mitschwingt, ist im Medium der Schrift überliefert und zitiert zudem in den ersten beiden Worten den Beginn einer anderen Schrift, das erste Buch Mose:

185 Derrida 1995, S. 167 f.

186 Für Ergänzendes zu Derrida und den Einwänden betreffend seine Logozentrismuskritik vgl. das Unterkapitel zum Forschungsstand. 
Im Anfang schuf Gott Himmel und Erde. (Genesis 1,1)

Im Anfang war das Wort, der Logos,

und der Logos war bei Gott,

und von Gottes Wesen war der Logos.

Dieser war im Anfang bei Gott. (Johannes 1,1-2) $)^{187}$

Am Anfang des Johannesevangeliums selbst steht nicht nur auf inhaltlicher Ebene das mündliche ${ }^{188}$ Wort Gottes, sondern eben auch ein schriftliches Zitat eines anderen schriftlichen Textes ${ }^{189}$ - womit sich, ähnlich wie schon bei der Metapher der Seelenschrift im Phaidros, quasi mit Derrida, gegen Derrida argumentieren lässt. Dabei drängt sich eine weitere These auf, nämlich dass selbst Derridas Kritik am abendländischen Logozentrismus, die aus ihr entwickelten Theorien und deren Einfluss eine jahrtausendjährige abendländische Tradition der Ewigkeitsbehauptung gegenüber Schriftzeichen letztlich - trotz höchsten Reflexionsgrades ${ }^{190}$ - noch weiter verstärkt haben.

\subsection{Das Problem der selbsterfüllenden Prophezeiung}

Zum bislang Dargelegten ist weiter zu ergänzen, dass auf der Ebene der Religion zumindest in Europa ein unmittelbares Konkurrenzmodell, das die Ewigkeitsbehauptung der christlichen, jüdischen und islamischen heiligen Texte radikal infrage gestellt hätte, fehlte resp. nach und nach verdrängt wurde:

187 Beide Stellen zitiert nach der Zürcher Bibel 2007, die in Joh. 1,1 absichtlich „Wort“ und „Logos“ nennt, um auf die Vielschichtigkeit der Bedeutung von altgriechisch lógos zu verweisen (vgl. ebd., NT, S. 144).

188 Wenn man „Logos“ mit „Im Anfang war das [gesprochene] Wort" übersetzt (vgl. Goethes Faust).

189 Natürlich hängt der Grad der Wortwörtlichkeit des Zitates generell an der Übersetzung des hebräischen Buch Mose ins Altgriechische resp. im vorliegenden Fall an der Übersetzung beider Stellen ins Deutsche. Dass aber grundsätzlich ein Zitat vorliegt, wäre schwerlich zu bestreiten. Damit wiederum bedient sich der erste Vers des Johannesevangeliums letztlich dreier innersprachlicher Verfahren, die je einer der im Hauptteil behandelten Grundoperationen zur Ewigkeitsattribuierung von Schriftzeichen zuzuordnen sind: 1) der Verwischung des Anfangs; vgl. die Unteroperation Unendliche Lektüre in Kapitel II.1; 2) der performativen Herstellung dessen, wovon die Rede ist, indem die Sequenz „Im Anfang“ aus der Genesis tatsächlich Worte sind, die „Im Anfang“ des Johannesevangeliums vorkommen; vgl. die Unteroperation Poetische Performativität in Kapitel III; und 3) dem autoreflexiven Verweis auf das eigene geschriebene Werk, das aus Worten besteht und das demzufolge auch mit Worten beginnt; vgl. die Grundoperation Reflexivität in Kapitel IV.

190 Oder vielleicht gerade wegen dieses Reflexionsgrades, wie eine Berücksichtigung der Ergebnisse dieser Arbeit zu Reflexionsphilosophie und Autoreflexivität in Kapitel IV. zeigen mag. 
Die zunehmende Dominanz des Christentums verdrängte die vorhandenen heidnischen Religionen, die entweder weitgehend mündlichen Kulturen entstammten oder nicht auf einer heiligen Schrift basierten. So erscheint es gerade auf der Ebene religiöser Überlieferung so, als ob die Behauptung, Schrift könne Vergängliches für alle Zeiten festhalten, sich bewahrheitet hätte: Unser heutiges Wissen um jene heidnischen Religionen Europas wäre (und ist in vielen Fällen) ohne schriftliche Zeugnisse sehr beschränkt. Vieles, was wir heute von diesen Religionen wissen, verdanken wir einerseits zeitgenössischen schriftlichen Überlieferungen jener Kulturen ${ }^{191}$ - von Hesiod über Ovid bis hin zu vereinzelten Runeninschriften religiösen Inhalts ${ }^{192}$ - oder aber der schriftlichen Überlieferung von Angehörigen, meist Klerikern, einer der Buchreligionen; man denke dabei im Falle der germanisch-nordischen Mythologie z. B. an Beowulf (siehe Punkt b. weiter unten) oder die Edda des Snorri Sturluson. Um wieder auf die oben zitierte Stelle in Platons Phaidros zurückzukommen, ließe sich daraus also plakativ formulieren: Diejenigen Religionen, die Sokrates' Präferenz gefolgt sind, mussten denjenigen, die den Weg umfassender Verschriftlichung gegangen sind, weichen. Auch hier geht es nicht darum, zu untersuchen, ob und wie stark der Siegeszug der Buchreligionen die Vorstellung, Schriftzeichen könnten Inhalte dauerhaft festhalten, gefördert haben mag, sondern im Gegenteil darum, darauf hinzuweisen, dass bei solchen Überlegungen aus mindestens zwei Gründen besondere Vorsicht geboten ist:

Erstens ist die Verdrängung heidnischer Religionen durch das Christentum auf zahlreiche und nicht mit absoluter Sicherheit feststellbare Faktoren zurückzuführen, unter denen die Grundlage eines heiligen Buches für sich wohl keine direkte Rolle gespielt hat. ${ }^{193}$ Der Erfolg des Christentums ist also erst einmal weder mit einem grundsätzlichen Erfolg der Schriftlichkeit gleichzusetzen noch mit einem Erfolg eines Buches, von dessen Texten ewige Gültigkeit behauptet wurde und wird.

Zweitens - und sowohl für eine Problematisierung der Ewigkeitsbehauptungen als auch für die vorliegende Arbeit viel relevanter - begegnet

191 Dies können Überlieferungen über die eigene oder aber auch über fremde Religionen sein, die zum Teil selbst keine oder kaum schriftliche Zeugnisse hinterlassen haben.

192 Vgl. Haarmann 1991, S. 458-465.

193 Indirekt war die Schriftkundigkeit für den Organisationsgrad kirchlicher Strukturen, die Vereinheitlichung der Lehre usw. natürlich von großem Vorteil. Über Schriftkundigkeit verfügten aber auch zahlreiche heidnische Kulturen ohne Buchreligion. Im Gegenteil waren umgekehrt die Verbreitung der griechischen Sprache sowohl im Osten als auch vor allem in urbanen Zentren des Westens des Römischen Reiches und die bereits vorhandene Schriftlichkeit größerer Bevölkerungsgruppen innerhalb des römischen Imperiums für die Ausbreitung der Buchreligion Christentum äußerst hilfreich (vgl. Lexikon für Theologie und Kirche, Bd. 7, Sp. 302-309). 
einem bei den Buchreligionen wieder, was bereits weiter oben im Falle des Phaidros gestreift wurde: der Aspekt einer selbsterfüllenden Prophezeiung, der wiederum in mindestens drei Varianten auftreten kann:

a) Bei der Analyse der Textstelle im Phaidros ging es um den performativen Widerspruch eines Textes, in dem die Figur Sokrates die Schrift als Förderer des Vergessens bezeichnet. Daran lässt sich hier anknüpfen: Wenn die Verschriftlichung tatsächlich das Vergessen fördern würde, nähme die Vergesslichkeit mit der Verbreitung der Schrift zu. In diesem Fall würde mit der Zeit höchstens noch das überdauern, was verschriftlicht wurde. Die Behauptung, dass die Schrift das Überdauern der mittels ihr festgehaltenen Informationen sichere, würde sich also nur deshalb bestätigen, weil die Schrift selbst wesentlich dazu beigetragen hat, dass alles andere vergessen ging.

b) Ob Verschriftlichung tatsächlich das Vergessen fördert, ist nicht Gegenstand dieser Arbeit, es ist jedoch allgemein bekannt, dass etwa auch soziale und politische Machtausübungen das Vergessen fördern oder massiv beschleunigen können (man denke etwa an die Stichworte damnatio memoriae). In einem solchen Fall kann der soeben beschriebene Mechanismus einer selbsterfüllenden Prophezeiung durchaus erfolgreich zum Einsatz kommen. Ein Beispiel dafür wäre das altenglische Gedicht Beowulf in Kombination mit Normen und Praktiken, die durch die Buchreligion Christentum geprägt sind: Ein zuvor mündlich tradiertes heidnisch-germanisches Heldengedicht wird von einem christlichen Schreiber in einen schriftlichen Text übertragen. In diesem Text wird der christliche Gott, wenn auch nur sehr oberflächlich, in die Geschichte integriert, um eine schriftliche Festhaltung einer heidnischen Geschichte zu rechtfertigen. ${ }^{194}$ Überdauert diese Geschichte nun auch in materieller Hinsicht (die Handschrift wurde während eines Brandes beinahe zerstört), dann hilft sie, die Ewigkeitsbehauptung gegenüber der Bibel zu bestätigen. Denn ein Gedicht, das u. a. auch von Gott handelt, hat überdauert. In Wahrheit aber hat das Gedicht nicht schriftlich überdauert, weil es von Gott handelte, sondern es verweist auf Gott, weil es verschriftlicht wurde.

c) Von da aus lässt sich wiederum überleiten zur im Zusammenhang mit der Ewigkeitsbehauptung simpelsten und am einfachsten anwendbaren Variante der selbsterfüllenden Prophezeiung: der (expliziten) Behauptung innerhalb eines Textes, dass das darin Verschriftlichte überdauern werde einer Behauptung, die uns vielerorts begegnet, so bereits im alten Ägypten, z. B. als Schlusssatz der Prophezeiungen des Neferti (20. Jahrhundert v. Chr.), ${ }^{195}$

194 Vgl. dazu zusammenfassend J. Frey 2013, S. 115 f.

195 „Ein Weiser wird mir Wasser sprengen [im Sinne eines Trankopfers, MG], wenn er sieht, / dass das, was ich gesagt habe, geschehen ist“ (zitiert nach J. Assmann 1991, S. 178). 
in Ovids Nachwort zu den Metamorphosen ${ }^{196}$ oder auch in Schillers Prolog zu Wallensteins Lager (vgl. Kapitel III.1.2). Gelangt der Text in lesbarem Zustand an kommende Generationen und findet unter ihnen Leserinnen und Leser, so bestätigt sich die Behauptung. Wird der Textträger hingegen zerstört, der Text unleserlich oder nicht mehr gelesen, so wird nie jemand erfahren, dass sich die darin enthaltene Behauptung nicht bewahrheitet hat. Diese Variante der selbsterfüllenden Prophezeiung ließe sich zudem genauso bei mündlichen Überlieferungen anwenden ${ }^{197}$ und beruht somit nicht auf einer genuinen Eigenschaft der Schrift.

Die soeben genannte Tradition der gerade auch von Dichtern gepflegten selbsterfüllenden Prophezeiung kombiniert sich im 18. Jahrhundert mit der Übertragung göttlicher Attribute auf das Individuum und dessen Werke sowie der damit einhergehenden Heiligung der Schrift als solcher. Bestes Beispiel dafür ist, was Thomas Wortmann zu Friedrich Gottlieb Klopstock schreibt: „Es ist die Heilige Schrift, die für Klopstock den idealen Stoff für das Epos bildet entsprechend versteht er die biblischen Propheten als Dichter und im Umkehrschluss avancieren die Dichter christlicher Epen zu den Nachfolgern der Propheten. ${ }^{“ 198}$

Mit jenen unter „zweitens“ zusammengefassten Varianten der selbsterfüllenden Prophezeiung rückt auch der Hauptteil der vorliegenden Arbeit immer näher. Denn es geht, wie bereits erwähnt, weder in dieser Einführung noch im Hauptteil um das Verfassen einer Geschichte der Ewigkeitsbehauptungen

196 „Doch mit meinem besseren Teil werde ich fortdauernd über die hohen Sterne erhoben werden, unser Name wird unzerstörbar sein, und so weit sich die römische Macht über den unterworfenen Erdkreis erstreckt, werde ich vom Mund des Volkes gelesen werden und, sofern an den Vorahnungen der Dichter auch nur etwas Wahres ist, durch alle Jahrhunderte im Ruhm fortleben“ (Ovid, Metamorphosen, S. 866 f.), wörtlichere Übersetzung nach MG, denn es ist hier entscheidend, bei der Übertragung von „nomenque [...] nostrum“ das ,unser' beizubehalten. Nur so wird nämlich die durch die mehrdeutige Deixis entstehende poetologische Ebene von "nostrum“ bewahrt, die den Namen Ovids sowie den Namen des Textes Metamorphosen selbst ineinander verschmelzen lässt. Mit dieser Verschmelzung wird Ovids behauptetes Überdauern an dessen eigene Metamorphose zu einem Text geknüpft und zugleich performativ vollzogen. Wie weiter unten anhand des Prologs zum Wallenstein ausführlich gezeigt, ist auch bei Ovid zu beobachten, dass bei ambitionierten Autoren Ewigkeitsbehauptung und Ewigkeitsattribuierung oft auf engstem Raum miteinander kombiniert werden. Im Falle von Ovids Nachwort wären die Unteroperationen Poetische Performativität und Poetologie zu beobachten.

197 Indem im Zuge einer mündlichen Äußerung behauptet wird, dieselbe würde auch noch an kommende Generationen weitererzählt werden. Wird sie samt dieser Behauptung mündlich tradiert, findet sich hier derselbe Effekt wie oben beschrieben.

198 Wortmann 2014, S. 87; vgl. dazu auch die Behandlung von Wortmanns Monographie im Unterkapitel zum Forschungsstand. 
bezüglich Schriftzeichen, sondern vielmehr darum, herauszufinden, welche innersprachlichen Operationen dazu eingesetzt werden, jene Behauptungen so weit wie möglich zu bestätigen. Der Mechanismus einer selbsterfüllenden Prophezeiung geht dabei stark in die Richtung der im Hauptteil unter Kapitel III behandelten Grundoperation der Autonomen Performativen Produktion und wird uns dort wieder begegnen. Doch zuerst sei noch einmal kurz zur Schriftlichkeit im Zusammenhang mit der Bibel zurückgekehrt:

Die Bibel als Heilige Schrift hatte sich als religiöse Grundlage Mitteleuropas bis ins 16. Jahrhundert bereits derart etabliert, dass die Reformation eine Rückkehr zur Heiligen Schrift ausrufen konnte. Ob dies im Grunde nicht doch vielmehr eher eine Rückkehr ${ }^{199}$ zu einer Praxis war, die es so nie gegeben hatte, sei hier dahingestellt; auch zeigt die Geschichte der Theologie, dass das Prinzip sola scriptura kein genuin reformatorisches Anliegen war, sondern bereits in der Scholastik "förmlich ausgebildet“ und „in den bibl[ischen] Reformbewegungen des Spätmittelalters (Waldenser, Hussiten usw.) kirchenkritisch geltend gemacht ${ }^{\text {"200 }}$ wurde. Zu bemerken ist aber, dass der von der Reformation durchaus forcierte Imperativ sola scriptura und insbesondere Luthers Vorstellung einer Heiligen Schrift, die für alle Zeiten „durch sich selbst ganz gewiss ist, ganz leicht zugänglich, ganz verständlich, ihr eigener Ausleger, alles von allen prüfend, richtend und erleuchtend“ ${ }^{201}$ die Ewigkeitsbehauptung gegenüber Schriftzeichen weiter verstärkt. Wer die Orientierung am biblischen Originaltext und dessen Fähigkeit zur Selbstauslegung - ob nun wortwörtlich (miss-)verstanden wie von zeitgenössischen Gegnern Luthers oder doch eher gemeint als (hermeneutischer) Prozess der collatio contraiorum in Christo conciliandorum ${ }^{202}$ - derart stark betont, ${ }^{203}$ impliziert und betont auch die Behauptung der ewigen Gültigkeit desselben und fördert

199 Vgl. etwa Luther, Assertio, S. 97; sowie Luther, Wahrheitsbekräftigung, S. 79-81.

200 Lexikon für Theologie und Kirche, Bd. 9, Sp. 703 f.

201 Luther, Wahrheitsbekräftigung, S. 81. Die viel erwähnte, aber selten korrekt zitierte Stelle lautet im lateinischen Original: „Oportet enim scriptura iudice hic sententiam ferre, quod fieri non potest, nisi scripturae dederimus principem locum in omnibus quae tribuuntur patribus, hoc est, ut sit ipsa per sese certissima, facillima, apertissima, sui ipsius interpres, omnium omnia probans, iudicans et illuminans, sicut scriptum est psal. c.xviii“ (Luther, Assertio, S. 97). Zu Luthers Sprach- und Schriftverständnis vgl. u. a. Ringleben 2010, insbesondere S. 252-443; Matsuura 2015; oder Mostert 1998.

202 Vgl. Matsuura 2015, S. 166.

203 Dies wird bis heute in der Theologie diskutiert, wie die in den vorangehenden Fußnoten genannten Publikationen zeigen. Zu ersten zeitgenössischen Einwänden von John Fisher und Erasmus von Rotterdam gegen die Formulierung „sui ipsius interpres“ vgl. u. a. Matsuura 2015, insbesondere S. $173 \mathrm{f}$. 
damit die oben festgestellte metonymische Übertragung resp. Ausdehnung der behaupteten Ewigkeit vom Inhalt auf das Medium.

In der Reformation erhält die Ewigkeitsbehauptung gegenüber Schriftzeichen also eine weitere, implizite, aber äußerst starke Fürsprecherin. Und auch hier, im Falle Luthers, der Reformation und deren Auswirkungen, findet sich wieder das Element einer selbsterfüllenden Prophezeiung, das nahe an die Grundoperation Autonome Performative Produktion zur Ewigkeitsattribuierung von Schriftzeichen heranreicht: Unter anderem gerade durch die Forderung sola scriptura kommt es zu einer Förderung der persönlichen Bibellektüre der Gläubigen, einer steigenden Alphabetisierung und dabei zusammen mit dem aufkommenden Buchdruck zu einer stärkeren Verbreitung der Heiligen Schrift und von Schriftlichem insgesamt, was wiederum letztlich erst die Möglichkeitsbedingung dafür schafft, sich auch selbst und im privaten Umfeld der Heiligen Schrift (und in einem weiteren Schritt: anderen Schriften) zuwenden zu können usw. ${ }^{204}$

\subsection{Von der Aufklärung bis ins 21.Jahrhundert: Übertragung eines göttlichen Attributes}

Zum Schluss dieser einleitenden Problematisierung der Ewigkeitsbehauptungen gegenüber Schriftzeichen sei derjenige Zeitraum in den Blick genommen, auf den die vorliegende Arbeit fokussiert: die zweite Hälfte des 18. und der Beginn des 19. Jahrhunderts. Um jedoch längere Überschneidungen mit den historisch-kontextualisierenden Kapiteln II.3 und IV.3 des Hauptteils zu vermeiden, gilt es, sich hier kurz zu fassen. Das Folgende ist denn auch eine knappe Zusammenfassung grundlegender, für die Problematisierung von Ewigkeitsbehauptungen relevanter Erkenntnisse aus diesen historischkontextualisierenden Kapiteln, die erst dort ausführlich behandelt werden, für die Lektüre des Hauptteils aber stets als zentraler historischer Hintergrund mitzudenken sind.

Der oben festgestellte, im Falle der drei monotheistischen Buchreligionen besonders akzentuierte Widerspruch zwischen der Flüchtigkeit und Vergänglichkeit des Mediums der Schrift auf semiotischer und materialer Ebene einerseits und den Behauptungen, sie könne ewig gültige Informationen ewig festhalten, andererseits bricht im Zuge der Aufklärung, gerade in Bezug auf die Bibel, erneut auf. Im Unterschied aber zur bisherigen theologisch-religiösen

204 Vgl. dazu auch A. Assmann 2015, S. 313-315 und auch 328, die in dieser Entwicklung die medien- und geistesgeschichtlich höchst wirkmächtige Ablösung der Hodegetik durch die Hermeneutik sieht. 
Argumentationslinie, ${ }^{205}$ die im Zweifelsfall die ewige Gültigkeit der göttlichen Botschaft gegenüber der Flüchtigkeit des Mediums der Schrift betonte, behaupten die spätestens in der zweiten Hälfte des 18. Jahrhunderts im abendländischen Diskurs dominanten - aber letztlich bis mindestens in die Renaissance und den Humanismus zurückreichenden ${ }^{206}$ - säkularen und säkularisierenden Argumentationslinien genau das Gegenteil. Dabei drehen sie jenes theologisch-religiöse Argument chiastisch um: Nicht die religiöse Botschaft wird gegenüber dem Medium der Schrift als ewig behauptet, sondern die Schrift als solche erhält verstärkt das Attribut der Ewigkeit, während die religiöse Botschaft diese immer mehr verliert. ${ }^{207}$

Während an der Wahrheit und erst recht an der ewigen Gültigkeit der biblischen Botschaften im Zuge der Aufklärung also immer mehr gezweifelt wird, ist parallel dazu eine Akzentuierung der expliziten und impliziten Ewigkeitsbehauptungen gegenüber der Schrift im Allgemeinen zu beobachten. Oder etwas plakativ formuliert: Dieser, Verlust' der Heiligen Schrift, der Bibel, führt zu einer zunehmenden Heiligung der Schrift als solcher.

Mit Letzterem einher gehen insbesondere die ästhetischen Auswirkungen der Reflexionsphilosophie, die Genie- als auch die Autonomieästhetik mit ihren enormen Einflüssen auf die Literatur- und Geistesgeschichte der Zeit um 1800 und der Moderne insgesamt (siehe Kapitel IV.3) und ebenso die Experimente in Richtung eines ewigen Schreibens sowie einer potenziell unbeendbaren Lektüre, die immer wieder auch die semiotische Flüchtigkeit von Schriftzeichen in den Dienst der Ewigkeitsattribuierung zu stellen suchen (siehe das Kapitel II.3).

ZumSchlussdieserkurzenundskizzenhaftenhistorischenProblematisierung lässt sich somit Folgendes zusammenfassend festhalten:

Offenbar waren im ,Abendland' die impliziten und expliziten Ewigkeitsbehauptungen gegenüber Schriftzeichen über eine mehr als zweitausendjährige Tradition bis zum 18. Jahrhundert bereits derart stark verankert, dass ausgerechnet die Aufklärung und die daraus hervorgegangenen literatur- und geistesgeschichtlichen Strömungen um 1800 sich nicht gegen sie gestellt haben, sondern wesentlich daran beteiligt gewesen sind, sie noch zu verstärken.

Dass die Ewigkeitsbehauptungen gegenüber Schriftzeichen bis heute Konjunktur, ja im 21. Jahrhundert geradezu Hochkonjunktur zu haben scheinen,

205 Man erinnere sich an den oben zitierten Textausschnitt aus Gryphius' Catharina von Georgien.

206 Vgl. u. a. A. Assmann 1999, S. 121-129, die dabei auch explizite humanistische Ewigkeitsbehauptungen gegenüber Schriftzeichen zitiert; sowie Nate 2018.

207 Vgl. dazu auch Neumann 2018. 
ließe sich schließlich an zahllosen Beispielen aus den unterschiedlichsten Bereichen aufzeigen, bis hin zur 2017 (erneut) ausgebrochenen Debatte über Sinn und Zweck der Germanistik, im Zuge derselben mancherorts frei nach Gadamer die Zeitlosigkeit der ,Klassiker' der Literatur beschworen wurde einer Tradition folgend, die, so wurde oben gezeigt, viel weiter zurückreicht als bis zu Gadamers Wahrheit und Methode. Besonders präsent ist aber die Verknüpfung jener alten Ewigkeitsbehauptungen gegenüber Schriftzeichen mit den neuen Medien und der fortschreitenden Digitalisierung: ${ }^{208}$ Die Phrase ,das Internet ${ }^{209}$ vergisst nie ist bereits zum Gemeinplatz geworden, was - lässt man berechtigte Bedenken bezüglich des Datenschutzes einmal beiseite - in historischer Hinsicht für ein derart junges Medium erstaunen mag und gerade auf semiotischer Ebene differenzierter zu betrachten wäre. Facebook bietet seinen Usern an, den jeweiligen persönlichen Account nach deren Ableben in einen virtuellen Grabstein umwandeln zu lassen, der zugleich als digitales Kondolenzbuch dient, mittels dessen die Hinterbliebenen die virtuelle Biographie des Verstorbenen gewissermaßen in aeternam fortschreiben können; ${ }^{210}$ und ambitionierte Programmierer arbeiten an dem Traum, einen Code zu schreiben, der eine künstliche Intelligenz möglich macht, die der menschlichen gleichkommt und selbst schöpferisch tätig zu werden vermag. Ob Letzteres je möglich sein wird, sei hier dahingestellt; zu erwähnen ist jedoch, dass jener Traum (von den jeweiligen Beteiligten erschreckenderweise weitestgehend unreflektiert) nichts Geringeres anstrebt als eine Kombination, an der sich bereits die mythologische Figur Pygmalion versucht hatte: eine Kombination des erschaffenen (Text-)Werkes, das nicht selber direkt schöpferisch tätig sein kann, mit dem biologischen Kinde, das die Gene seiner Schöpfer - in diesem Falle den von ihnen geschriebenen Code - weiterträgt und selber Trieb und Möglichkeit zum eigenständigen Erschaffen besitzt. Eine Kombination der beiden eingangs zitierten, von Diotima genannten Möglichkeiten, Unsterblichkeit zu erlangen.

\footnotetext{
208 Vgl. auch J. Assmann 2003, S. 46; und Krüger 2004.

209 Sowohl der Begriff Internet als auch World Wide Web verweisen auf ein aus unterschiedlichsten miteinander verwobenen Fäden bestehendes, weltweites Netz, ein weltweites Gewebe resp. Textum, sie konstituieren also eine Textmetapher.

210 Vgl. dazu auch Brukamp 2011.
} 